\title{
Physical, Emotional, and Social Pain During COVID-19 Pandemic-Related Social Isolation
}

\author{
Priscila Medeiros ${ }^{1,2}$ - Ana Carolina Medeiros ${ }^{1,2,3}$. \\ Jade Pisssamiglio Cysne Coimbra ${ }^{4}$. Lucas Emmanuel Pedro de Paiva Teixeira ${ }^{5}$. \\ Carlos José Salgado-Rohner ${ }^{6}$. José Aparecido da Silva ${ }^{7}$ (D) . \\ Norberto Cysne Coimbra ${ }^{1,3}$ (iD $\cdot$ Renato Leonardo de Freitas ${ }^{2,8,3}$ (iD
}

Accepted: 31 January 2022

(c) Associação Brasileira de Psicologia 2022

\begin{abstract}
The socio-emotional condition during the COVID-19 pandemic subsidises the (re) modulation of interactive neural circuits underlying risk assessment behaviour at the physical, emotional, and social levels. Experiences of social isolation, exclusion, or affective loss are generally considered some of the most "painful" things that people endure. The threats of social disconnection are processed by some of the same neural structures that process basic threats to survival. The lack of social connection can be "painful" due to an overlap in the neural circuitry responsible for both physical and emotional pain related to feelings of social rejection. Indeed, many of us go to great lengths to avoid situations that may engender these experiences. Accordingly, this work focuses on pandemic times; the somatisation mentioned above seeks the interconnection and/or interdependence between neural systems related to emotional and cognitive processes such that a person involved in an aversive social environment becomes aware of himself, others, and the threatening situation experienced and takes steps to avoid daily psychological and neuropsychiatric effects. Social distancing during isolation evokes the formation of social distress, increasing the intensity of learned fear that people acquire, consequently enhancing emotional and social pain.
\end{abstract}

Keywords Social distancing $\cdot$ Social pain $\cdot$ Emotional pain $\cdot$ Neuroscience . COVID-19

Priscila Medeiros

priscila.neuro@usp.br

$\triangle$ Renato Leonardo de Freitas defreitas.rl@gmail.com

Extended author information available on the last page of the article 


\section{Introduction}

\section{Victims of The Alienist}

The discussion regarding the consequences of social isolation on human health is not a novelty, considering that these factors have been studied since 1987 in Brazil; that study characterised the beginning of the Psychiatric Reform Movement (Brazilian Health Ministery, 2018). Since the times of the Brazilian Empire, under the reign of Dom Pedro II, there have been asylum hospitals in which people were submitted to long-lasting social isolation due to mental diseases.

These psychiatric hospitals separated patients with mental illnesses from healthy people, putting together patients considered unsuitable for a social relationship. According to Saraceno (1999), asylum is a variable independent of the socioeconomic conditions of the country in which it is situated, as it is a place for resetting the exchange of social norms.

In asylums, people were hospitalised for several years, sometimes until their death, as reported by Maurício Lougon's experiences (Lougon, 2006) during the de-institutionalisation of Juliano Moreira Colony, from 1982 to 1985, highlighting the hospitalisation of 2600 patients, the majority of whom were elderly individuals, who lived years of their lives suffering various kinds of abandonment, violence and social isolation.

The psychological consequences of long-lasting hospitalisation in asylums, such as the Juliano Moreira Colony, are the following: (a) a lack of autonomy of patients regarding the choice of medical treatment and forced familial exclusion and (b) the limitation of the physical spaces and social experiences in society, highlighting that the psychiatric hospital becomes the residence of the patient with mental diseases. In this case, the patient's life is limited to psychiatric hospital activities, searching for meaning for their lives and daily routines but facing emotional pain caused by the absence of their family and existing homes (Salles \& Barros, 2013).

In recent decades, the Psychiatric Reform Movement led to better medical care and more attention being placed the mental health of these patients who have lived for years under bad sanitary conditions and who were socially isolated (Lougon, 2006). New approaches were established, such as therapeutical houses, psychosocial care centres, the Homecoming Programme, acquaintanceship and cultural centres, and mental health clinics, that allowed patients to develop feelings of autonomy regarding their own life, develop healthy social relationships, improve their mental health, to have the opportunity to work, and to experience better living conditions (Salles \& Barros, 2013).

Interestingly, as illustrated in The Alienist (de Assis, 1998), in the new world context of the COVID-19 pandemic, people considered healthy were suddenly obligated to socially isolate themselves inside their homes, or even in places far from their familial homes, due to their work requiring them to be beside potentially infected people. The social isolation caused by the COVID-19 pandemic also caused people to exhibit poor affective behaviour as they could not 
participate in traditional social events, such as funerals, weddings, and anniversaries and were isolated from parents infected by the COVID-19 pathogen (Danzmann et al., 2020).

The social isolation caused by COVID-19-related quarantine may cause severe post-traumatic stress disorder, not only due to pandemic fear but also due to unemployment, loss of parents without being able to mourn in the traditional way, and the risks of traumatic familial experiences, such as those in which children, adolescent and women are forced to isolate themselves from society while coexisting daily with a potential aggressor in the same environment or experiencing a non-escapable threatening situation, similar to patients with mental diseases faced abandonment when they forgotten inside asylums in the past.

Health professionals aiming to prevent additional psychological damage must carefully manage possible stigmatisation of both infected and healthy people, in addition to people subjected to experiencing aggressive social interactions inside their homes, chronic stress, fear, sadness, helplessness, and jitters, may cause increased serum levels of cortisol and consequently may cause immunological system impairment, susceptibility to other diseases and COVID-19 reinfection.

\section{Impact on Physical and Mental Health Caused by Social Isolation}

The COVID-19 pandemic is a global public health risk that profoundly affects every aspect of human life. Due to high transmissibility and the lack of an efficient vaccine capable of immunising the population, restrictive measures such as social isolation are implemented and encouraged (Zhai et al., 2020). The current question is based on the perspective that while the social impacts of isolation meet public health benefits, psychological and neuropsychiatric problems can be triggered by isolation (Abad et al., 2020; dos Cardoso et al., 2021; Wang et al., 2017). As a result, social isolation may be regarded as a risk factor equivalent to the harmful effects caused by smoking and obesity (Holt-Lunstad et al., 2010), causing a reduced well-being and an increase in depression (Heikkinen \& Kauppinen, 2004; Meléndez et al., 2020), cognitive decline (Ismail et al., 2021; Wilson et al., 2007), pain (Aslund et al., 2010; Karayannis et al., 2019) and increased mortality (Patterson \& Veenstra, 2010; Steptoe et al., 2013). This trigger may be more problematic in older people due to their decreasing economic and social resources, functional limitations, the death of relatives and spouses, and changes in family structures and mobility (Administration on Aging, 2013).

The prevalence of COVID-19 in the community is uncertain because people may not present symptoms. Therefore, mortality reports may be as low as $0.6 \%$ (Wilson et al., 2020). Older persons have a much higher mortality risk, comprising about $15 \%$ than younger persons (Wilson et al., 2020). In fact, the risk increased in people with comorbidity (de Paiva Teixeira et al., 2020). Persons with hypertension and diabetes mellitus are at increased risk, possibly due to alterations in the angiotensinconverting enzyme 2 (ACE 2) receptor produced by ACE 1 inhibitors.

Primary prevention, especially for older patients with comorbidity, consists mainly of social distancing and, when possible social isolation. For older persons, 
the problem with social isolation could be loneliness (Berg-Weger \& Morley, 2020). Loneliness leads to depression, cognitive dysfunction, disability, cardiovascular disease, and increased mortality. Prevention also requires regular hand washing and cleaning of surfaces. Wearing a mask does not protect the individual. Then, the vaccine has shown higher protective effects in older adults (Soiza et al., 2021).

Social participation is an excellent stimulus for the elderly. Social events promote physical activity and the interaction with other elder people, as a putative stimulus to the sensory system, self-esteem, affectivity, and provide emotional and psychological support, consequently improving motor and cognitive functions (Douglas et al., 2017; Loyola et al., 2017; Sepúlveda-Loyola et al., 2020; Tomioka et al., 2015).

Thus it is expected that the elderly population will suffer even more from social isolation. It is known that social isolation could have a negative impact on mental activity (Croezen et al., 2015, Morley \& Vellas, 2020), enhancing the risk of depression (Courtin and Knapp, 2017), emotional disturbance (Yoon et al., 2016), stress (DiGiovanni et al., 2004), low mood and irritability (Lee et al., 2005), or insomnia (Lee et al., 2005), and is also associated with higher rates of suicide in the elderly population (Yip et al., 2010).

Research shows that social isolation and loneliness have an impact on health. However, it is interesting to mention that different dimensions (objective or subjective) are investigated in this construct of social isolation (Cornwell \& Waite, 2009; Valtorta et al., 2016). Objective social isolation is the physical separation from, the absence of, or the inability to interact with other people. Tools that address participation in groups, social activities, and events; the frequency and social network have been investigated (Cornwell \& Waite, 2009; Coyle \& Dugan, 2012; Valtorta et al., 2016). Subjective social isolation is characterised by self-perceptions and quality of the relationships between a given person and members of his/her social networks and perceived integration and involvement in social networks (Valtorta et al., 2016).

Coyle and Dugan (2012) also showed that both loneliness and objective social isolation were significantly related to a mental health problem. Notably, both objective and subjective isolations are correlated but do not have the same constructor (Shankar et al., 2013). That phenomenon shows that when people have experienced objective social isolation, they may or may not feel subjectively isolated (Coyle \& Dugan, 2012).

\section{Social Isolation and Pain}

Studies suggest that social relationships have an essential role in pain. Individuals with larger self-reported social group sizes showed higher pain tolerance (Johnson \& Dunbar, 2016). Experimentally induced social exclusion and perceived social support increase and reduce the severity of acute experimental pain, respectively (Brown et al., 2003; Eisenberger et al., 2006; Master et al., 2009). Conversely, poor relationships and self-imposed isolation have been correlated with chronic pain (Smith \& Osborn, 2007; Snelling, 1994).

Hormonal stress responses and anxiety are evoked by social isolation when occurring in the early life of adult rodents, and social support can play a role as a 
buffer against stress (DeVries et al., 2003). Moreover, there is evidence that social distress potentiates sensitivity to physical pain (Aslund et al., 2010). Eisenberger et al. (2006) also showed that socially excluded individuals displayed lower pain thresholds to unpleasant heat stimuli. In addition, pain coping and social support during early rheumatoid arthritis (AR) can beneficially influence long-term outcomes in AR (Evers et al., 2003). In addition, chronic musculoskeletal pain is associated with perceived social support and pain interference (Ferreira-Valente et al., 2014).

Biopsychosocial factors are also frequently regarded as significant factors that can increase the risk of poor prognosis of low back pain, but the "social" component in the biopsychosocial model has received little attention. Perceived social isolation is prevalent in patients with low back pain of any duration (Hawthorne et al., 2013), and this can be a crucial but underinvestigated prognostic factor for that condition. The point prevalence of patients who perceive at least some social isolation is $43 \%$ when they have low back pain, 24\% higher than the general population (Hawthorne et al., 2013).

Che et al. (2018) suggest that the impact of social support on pain is contextdependent, with the verbal communication of support and intimate relationships being of particular importance. Interpersonal touch and social support can influence physical health, mental well-being, and pain. In addition, social support can reduce pain by changing the value of nociceptive signals. This reduction may be moderated by interpersonal synchrony and relationship dynamics (Reddan et al., 2020).

Social support has modulated pain and pain-related arousal for several decades. However, it may impact physiological arousal, the mere presence of another person. In fact, social support decreases pain when it is more clearly expressed, as verbal communication and handholding. Shreds of evidence further highlight the significance of intimate relationships in emotion communication and pain reduction, considering that social support can decrease pain (Che et al., 2018).

Pain in subjects undergoing confinement is persistent, with varying intensity and frequency based on age, gender, physical activity, and work status. In any of these conditions, the quality of life of the subjects in confinement has been severely affected, which creates a severe public health problem (Iglesias-López et al., 2021).

Moreover, individuals who experienced intense pain during COVID-19 infection have higher fear of pain and lower quality of life. In addition, as the fear of pain increases, the quality of life of individuals decreases (Korkut \& Ülker, 2021). Multidisciplinary biopsychosocial rehabilitation interventions are more effective than usual care (moderate-quality evidence) and physical treatments (low-quality evidence) in decreasing pain and disability in people with chronic low back pain. For work outcomes, multidisciplinary rehabilitation seems to be more effective than physical treatment but not more effective than usual care (Kamper et al., 2015).

Thus, most of the included studies showed a link between multimorbidity and increased loneliness. However, there is a lack of studies examining the association between multimorbidity, social isolation, and social frailty. Future studies are necessary to shed light on these crucial associations. Naturally, it is essential in times of the COVID-19 pandemic. 
Recurrent pain episodes have also been associated with a lack of understanding of endometriosis symptoms and women's resignation during social isolation (Mellado et al., 2016). The inflammatory and immunologic factors are modified during endometriosis, and social isolation may also change these conditions. In fact, social isolation can interfere with endometriosis through these factors (Cacioppo et al., 2011).

The sequelae of perceived social isolation associated with chronic pain include maladaptive responses, work loss, and financial security, being anxious with others, experiencing loss of traditional family roles, losing care and concern for others, sexual dysfunction, depression, anxiety, and realising that others do not understand the life lived with low back pain (Bowman, 1994; Schwartz \& Slater, 1991).

Depressive symptoms are essential to consider when interpreting the link between social and physical health. Individuals with low back pain and higher baseline depression experienced a slower recovery process (Melloh, Elfering, Stanton, et al., 2013b). Individuals with depressive symptoms and acute and subacute episodes of low back pain (LBP) were more likely to have persistent pain in a 6-month follow-up (Melloh, Elfering, Käser, et al., 2013a).

In laboratory animals, the social isolation altered the neurochemical systems, for example enhancing presynaptic dopaminergic function in the nucleus accumbens and the prefrontal cortex, presynaptic serotonergic function, and cause an imbalance in dopamine and 5-hydroxytryptamine (5-HT) in the frontal cortex (Crespi et al., 1992; Fone et al., 1996; Jones et al., 1992). Animals isolated during infancy display a long-lasting effect on acute heat pain sensitivity, primarily disturbing C-fiber-related pain pathways, suggesting a selective disruption in the ascending anterolateral spinal-thalamic pathways (Tuboly et al., 2009). Moreover, the housing conditions are a critical factor evoking modifications in pain perception in animals, and it was also shown that isolation of juvenile animals caused significant changes in pain sensitivity, which might be due to changes mainly in the number and activity of $\mu$-opioid receptors (Defeudis et al., 1976; Van Den Berg et al., 1999).

\section{Multiple faces of pain pathways: from nociception to pain perception}

According to the International Association for the Study of Pain (IASP), nociception is referred as "activity that occurs in the nervous system in response to a noxious stimulus," whereas pain is "an unpleasant sensory and emotional experience associated with or resembling that associated with, actual or potential tissue damage" (Raja et al., 2020). Nociception thus includes the mechanisms by which noxious stimuli are detected by the peripheral nervous system, encoded, transferred, and unconsciously processed by the central nervous system structures.

Sensitisation of sensitive fibres, including nociceptive fibres, a key-phenomenon after injury or inflammation, which results in the release of chemical mediators by different cells. The released chemical mediators act by directly activating the nociceptors or sensitising them (Julius, 2001; Kandel et al., 2000).

Chemical mediators can activate or sensitise nociceptors, which are free nerve endings of pseudo-unipolar neurons dendrites, whose cell bodies are found in the ganglia of the dorsal root of the spinal nerve and trigeminal nerve sensory ganglion 
that process these traumatic or inflammatory stimuli (Kandel et al., 2000; Le Bars et al., 2001; Messlinger, 1997; Millan, 1999). The axons of these pseudo-unipolar neurons, called primary afferent fibres, carry nociceptive information to the central nervous system.

Three types of receptors for free nerve endings are associated with two types of primary afferent nerve fibres. Considering a functional criterion, they are (a) mecha-

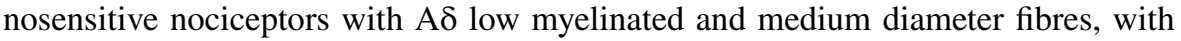
conduction speeds of 5 to $30 \mathrm{~m} / \mathrm{s}$; (b) mechanothermal nociceptors with A $\delta$ fibres, and (c) polymodal nociceptors with not myelinated $\mathrm{C}$ fibres of small diameter with a conduction speed of about $1 \mathrm{~m} / \mathrm{s}$, which respond to thermal, mechanical and chemical stimuli (Julius, 2001; Millan, 1999).

The nociceptive stimulus recruits peripheral nociceptors that carry the nociceptive signal to the first somatosensory neuron located in the dorsal root ganglion of the spinal nerve, which connects with the second-order neuron located in the dorsal horn of the spinal cord. It is precisely situated on II, III, and V Rexed's laminae, of the dorsal horn of the spinal cord, in which the primary afferent neuron makes the first synapse with the second neuron (Fig. 1). The second neuron sends axons that will form the neospinal-thalamic and paleospinal-thalamic tracts after crossing the median plane of the spinal cord and sends afferent ascending projections to the great supraspinal centres, such as the reticular formation, the limbic system, the posterolateral ventral nuclei (neospinal-thalamic pathway-related nucleus) and intralaminar nuclei (paleospinal-thalamic pathways) of the dorsal thalamus (Marchand, 2012) (Fig. 1).

The trigeminal component of the anterolateral system has its first-order neurons in the Gasser's semilunar ganglion, which establishes synapses in the spinal nucleus

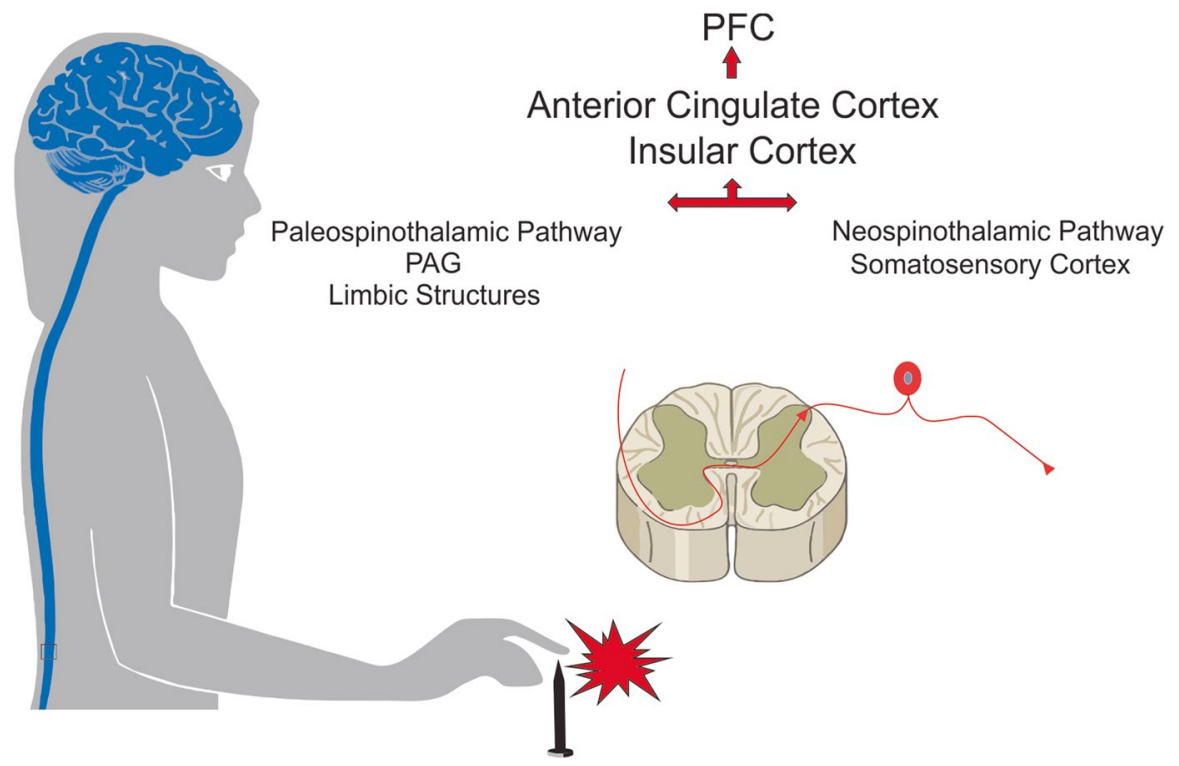

Fig. 1 Pain pathways from nociception to sensory discriminative perception and emotional pain 
of the trigeminal nerve, where the second-order neurons of the pathway are located; the axons of these second-order neurons cross the midline and comprise the trigeminal lemniscus, which enters the posteromedial ventral nucleus of the dorsal thalamus. Spanning from the dorsal thalamus, through the corona radiata, third-order neurons connect with the somesthetic cortex, spreading somatotopically (Marchand, 2012).

It is important to emphasise that second-order neurons can connect with different brain stem nuclei, including the periaqueductal grey matter (PAG) and the nucleus raphe magnum (NRMg), which are areas involved in the endogenous downward modulation of the pain system. The primary $\left(\mathrm{S}_{1}\right)$ and secondary $\left(\mathrm{S}_{2}\right)$ somatosensory cortexes, which receive afferents from the dorsal thalamus, are involved in the quality of the sensory perception of pain, which includes the location, duration, and intensity of pain. Tertiary neurons also project to limbic structures, including the anterior region of the cingulate gyrus cortex $\left(\mathrm{Cg}_{1}\right)$ and the insula, which are involved with the affective and emotional components of pain (Marchand, 2012), as well as the hypothalamic nuclei, parabrachial area and amygdaloid complex (Hammond, 1989). These connections emphasise that pain is more than the activation of sensory components. The anterior cingulated cortex also sends glutamatergic inputs to the posterior hypothalamic nucleus, modulating the perception of painful stimuli in a threatening situation (Falconi-Sobrinho et al., 2017).

Additionally, the perception of pain is mediated by perceptual processes; depending on how the stimulus is perceived, the pain sensation may vary (Lucchelli et al., 1978; Schapira et al., 1970). In addition, several studies have shown that the physical form of drugs and their appearance placebo-like effect can alter their effect in cases of pain treatment (Bar \& Neta, 2006, 2007; RE and LW 1984; Silvia \& Barona, 2009; Westerman et al., 2012). Moreover, it has even been shown that stimuli associated with pleasure, liking, and disgust are also related to changes in the perception of the effect of medication (Wan et al., 2015).

\section{Emotional Aspects of Pain}

According to IASP, approximately one in five people suffer from chronic pain worldwide. The effects on quality of life are devastating. A study published in 2006 analysed 126 patients with chronic pain and found that the group had several affective and cognitive impairments, such as insomnia $(60 \%)$, difficulty concentrating (36\%), depression (33\%), and anxiety (27\%). Even the professional lives of the affected people seemed to be affected; more specifically, $52 \%$ of the participants had losses at work due to pain (Breivik et al., 2006).

Over the past few decades, the influence of anxiety on pain perception has been extensively investigated. Anxiety is accepted as one of the determining psychological factors in the subjective experience of pain (Tang \& Gibson, 2005). Asmundson et al. (1996) pointed out a link between anxiety disorder and pain, demonstrating that the prevalence of anxiety is higher in people who suffer from chronic pain. 
Furthermore, $45 \%$ of chronic pain patients also had an anxiety disorder (Asmundson \& Katz, 2009).

Knaster et al. (2012) showed that the diagnosis of anxiety disorder precedes the onset of pain in more than $75 \%$ of individuals. Similarly, Shaw et al. (2010) revealed that patients who suffered from low back pain were 2.45 times more likely to develop chronic low back pain when diagnosed with a generalised anxiety disorder.

There is a high association of comorbidity between anxiety and chronic pain, and some researchers postulate that this type of pain may be an expression of chronic post-traumatic stress disorder (Grande et al., 2004; Otis et al., 2003). There are functional and metabolic similarities between neuropathic pain and post-traumatic stress disorder, with the mPFC playing a key role in integrating the disorder and comorbidities (Feldman, 2004). There are reports in the literature showing in both human patients and laboratory animals that the presence of chronic pain causes changes in functional reorganisations in cortical and subcortical structures, including the mPFC (Apkarian et al., 2009; Baliki et al., 2006; Medeiros et al., 2019a, b, c; Malvestio et al., 2021; Metz et al., 2009), dorsal thalamus (Apkarian et al., 2004), amygdaloid complex (Han et al., 2005; Ji et al., 2010), and anterior cingulate cortex (ACC) (Li et al., 2010).

Considering the pain pathways, nociceptive stimuli elicit action potentials that pass through the anterolateral system and the neospinothalamic tract, an essential spinal-thalamic tract, and reach the primary somatosensory cortex through the specific thalamus-cortical system; these stimuli are involved in the physical sensation of pain (Lumley et al., 2011). The affective experiences of pain-related connections reach supraspinal brain structures through the paleospinothalamic tract, which recruits the periaqueductal grey matter, amygdaloid complex, parabrachial area, hypothalamus, and insula (Hammond, 1989; Lumley et al., 2011; Vogt et al., 1993)

Information from these pathways comes together in the ACC and insular cortexes. Thus, the combination of nociceptive and affective inputs to these areas elicited by the same stimulus influences interoceptive homeostasis (Craig, 2003) and response prioritisation (Lumley et al., 2011; Price, 2000a). Hence, both types of information about pain contribute to our subjective experience and, ultimately, our response to it. From this theory, we seek to establish the anatomical links between emotions and pain (Fig. 1).

Several areas are activated in PET and fMRI studies when pain is involved. The second somatosensory $\left(\mathrm{S}_{2}\right)$ and insular cerebral regions and the ACC are the cortical areas most consistently activated during the experience of pain (Cauda et al., 2012; Peyron et al., 2000). The thalamus is often activated as an intermediate diencephalic interface regarding the somatosensory ascending neural pathways. These areas reflect the activation of the anterolateral system, especially where the spinal-thalamic tracts converge on the insula and ACC. Meta-analytic connectivity modeling was utilised to identify active areas across multiple types of stimuli, as well as attentional, emotional, and reward tasks (Cauda et al., 2012) (Fig. 1).

The insula, dorsal ACC, and thalamus were again consistently activated. The neural activity in these structures reflects both external inputs of pain and the internal reflection on pain, much in line with Melzack and Casey's two-stage theory of pain described previously in brief (Melzack \& Casey, 1968). The ACC appears to 
be particularly important in the affective interpretation of pain. Some investigations dissociated the circuitry involved in the emotional and attentional modulation of pain and showed that the ACC was the largest modulator of mood and influenced pain unpleasantness but not pain intensity. Attentional modulation associated with pain intensity was not robust but activated the anterior insular cortex (Villemure \& Bushnell, 2009).

ACC likely acts as a mediator between cognition and emotion, with connections to the limbic system structures (Falconi-Sobrinho et al., 2017) and prefrontal cortex (PFC), as well as to somatosensory areas (Stevens et al., 2011). Because the ACC is closely linked with affective processing and is consistently activated during the experience of pain, the ACC likely plays a role in affective regulation during the experience of pain (Zugaib et al., 2014; Zugaib \& Menescal-de-oliveira, 2017). Both emotional and physical pain elicit activity in these common areas, and conditions that affect one system (e.g., drugs, neural plasticity) may affect the function of the other, ultimately altering the experience of pain. Finally, we might consider other neural pathways, limbic and paralimbic structures as putative neural substrates for fear-related reactions and pain control during threatening situations, such as diencephalic and midbrain structures and connections (Freitas et al., 2009; de Freitas et al., 2013; Ullah et al., 2015; Almada and Coimbra, 2015).

\section{Neurobiological Aspects of Social Pain}

Due to this close link, emotional pain appears to mimic certain aspects of physical pain in terms of brain activity and pain perception. For example, social rejection elicits similar activation in the same areas as physical pain, and greater sensitivity to physical or social pain is associated with greater sensitivity to physical pain. Social organisation is not an exclusive characteristic of human beings; social ties are essential for the well-being and survival of mammals (Baumeister \& Leary, 1995).

Due to the impossibility of self-care after birth and during the postnatal period, mammals need the support of a caregiver. Thus, this lengthy period could have facilitated a "system of social ties." This system, in turn, could use aspects of the physical pain system to "alert" us when we have lost a social bond. The distance from a caregiver is a threat to survival. Feeling "hurt or anguished" with this separation leads the threatened person to develop adaptive strategies to avoid such distances (Panksepp, 1998).

Social ties are essential for survival. Thus, using a social attachment system and the physical pain system will capture attention and alert us to real or potential damage in social relationships (Panksepp, 1998). In this sense, social isolation, like what we live in due to quarantine measures during the COVID-19 pandemic, can cause unpleasant experiences, described as pain, and recruits at least part of the same neurobiological substrates that underlie experiences of physical pain. Multiple ascending pathways carry physical pain information to supraspinal structures, adding aspects of autonomic system activation, escape, motor orientation, arousal, and fear 


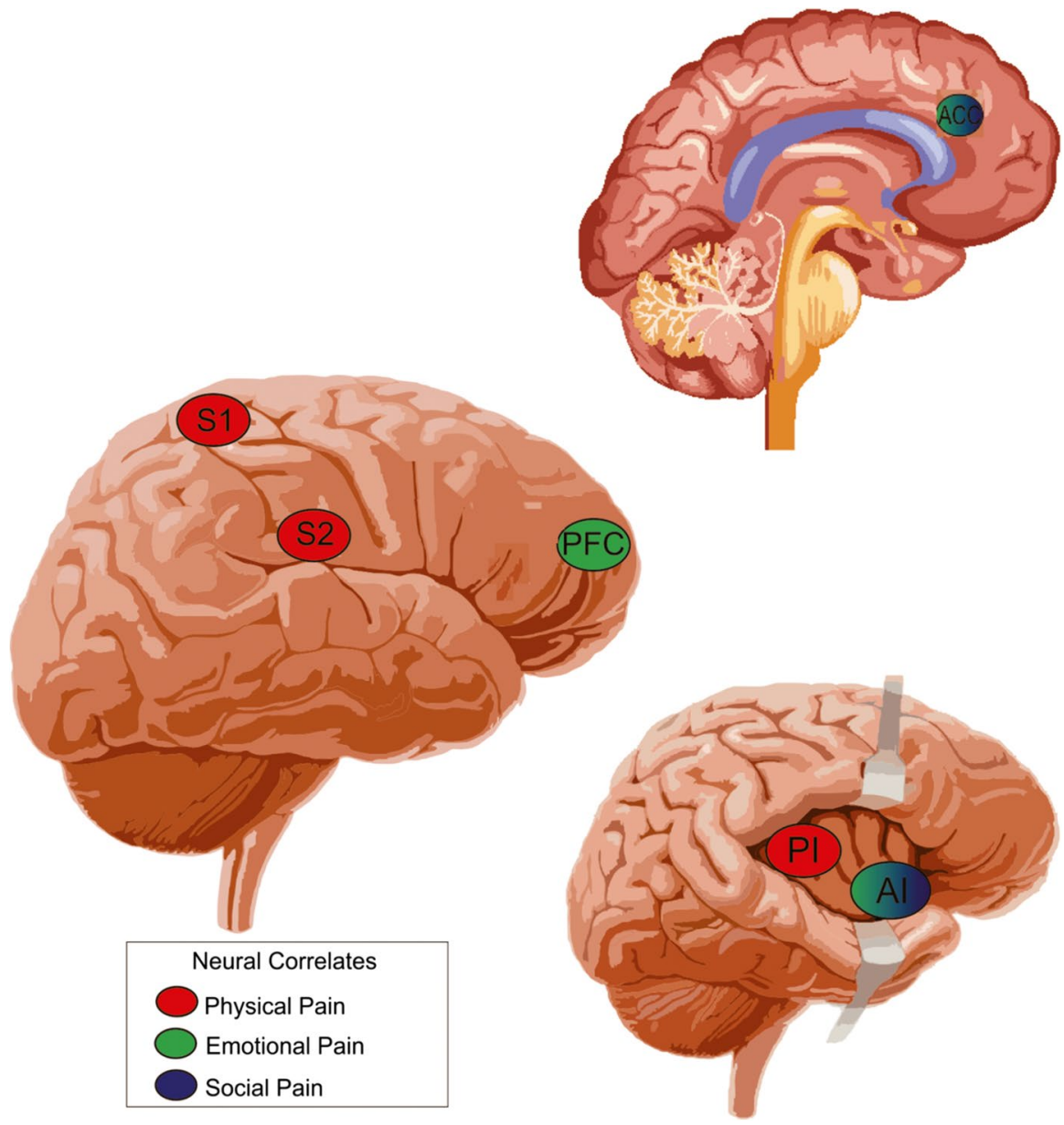

Fig. 2 Brain areas that have been shown to be related to physical pain, emotional pain, and social pain. S1: Primary somatosensorial cortex; S2: Secondary somatosensorial cortex; ACC: anterior cingulate cortex; PFC: prefrontal córtex; AI: anterior área of the insula; PI: posterior área of the insula

(Price, 2000). The integration between somatosensory inputs and cognitive aspects also occurs in posterior parietal cortical areas (Friedman et al., 1986).

Nociceptive information pathways that integrate structures such as the insular cortex and amygdaloid complex converge at the level of the ACC, a mechanism by which somatic perceptual and cognitive characteristics of pain would be integrated with rudimentary attentional and emotional mechanisms (Price, 2000) (Fig. 2). Thus, the ACC coordinates the association of somatosensory characteristics of pain with prefrontal brain mechanisms involved in the association of significance and long-term implications for pain (Fig. 2).

Studies show the involvement of these areas in the processing of physical pain and social pain. Social pain is defined as an unpleasant experience that is 
associated with actual or potential damage to one's sense of social connection or social value; such unpleasant experiences include social rejection, exclusion, negative social evaluation, or loss (MacDonald \& Leary, 2005). An analysis of neuroimaging data has shown the activation of structures such as the dorsal part of the ACC (dACC) and anterior area of the insula (AI) in individuals who have experienced social exclusion (Eisenberger, 2012a). These regions are known to play a role in the distressing experience of physical pain. Moreover, the dACC and AI may have a modulatory role in the links between social rejection and inflammatory activity and depression. Concerning the sensory-discriminative and affective-motivational components of pain, the latter is related to aspects of emotion, arousal, and behavioural programming (Treede et al., 1999) (Fig. 2).

In this way, the processing of social suffering is dependent on the activity of brain regions associated with the affective component of pain, involving the prevention of damaging social outcomes and serving as a punishment-based reinforcement to teach organisms to avoid threatening stimuli in the future.

In investigations using laboratory animals, damage in ACC dorsal and/or ventral areas reduces anguish-related vocalisations, which are behaviours related to social separation in non-human mammals. In experiments of isolation and maternal separation, the PAG is another encephalic area involved in suffering processing (Hadland et al., 2003).

In human beings, cingulotomy induces decreased self-awareness, together with reduced concern for other people's opinions or social judgments (Tow \& Whitty, 1953). Associated with cingulotomy, patients can still feel and localise pain sensations (sensory component intact), but the pain no longer "bothers" them (Foltz $\&$ White, 1968). In addition, individuals with more social support or who spend more time with friends show reduced activity in the dACC and insula in response to social exclusion (Eisenberger, Taylor, et al., 2007b). In contrast, more significant self-reported social disconnection during real-world social interactions is associated with more significant activity in the dACC and PAG in response to social exclusion (Eisenberger, Gable, \& Lieberman, 2007a). In this sense, there is support in the literature for the critical role played by the ACC in processing the distress associated with social separation or disconnection.

Another aspect that can be changed due to social isolation is the inflammatory process and changes in the transcriptional activity of the human genome. The increased activity of pro-inflammatory transcription controls neural pathways with glucocorticoids responsible for the high risk of inflammatory disease in individuals who experience chronically high levels of subjective social isolation (Wager et al., 2009). Furthermore, the increased activity of the dACC and AI in a stressful situation and/or social isolation can contribute to an increase in inflammatory activity (Wager et al., 2009). The increased circulation of pro-inflammatory cytokines, such as IL-6, mediates the relationship between social exclusion and depression and is related to the intensity of pain in some populations (Sturgeon \& Zautra, 2016).

From a neurochemical perspective, opioids have already been shown to affect emotional behaviour of laboratory animals submitted to the elevated plus maze test of anxiety (Anseloni et al., 1999) and reduce the distress associated with separation (Eisenberger, 2012a). The endogenous opioid system is associated with regulating 
the distress caused by the physical pain-inducing neurochemical regulation of the distress associated with social separation. In animals, low doses of exogenous opiates reduced distress-induced vocalizations of socially isolated puppies as well as the pleasure associated with social connections (Panksepp et al., 1978). According to Way et al. (2009), individuals with the G allele showed greater reactivity to social rejection in encephalic structures (dACC and AI) previously demonstrated to be involved in social and physical pain processing. Thus, the dACC is considered a critical place for the influence of opioids on social pain. The authors suggest that the A118G polymorphism, specifically related to the $\mu$-opioid receptor, is generally involved in both social and physical pain (Way et al., 2009).

In rodents, social isolation is associated with a decrease in neurogenesis in the hippocampus, increased cortisol levels (indicative of stress), and anxiety-like behaviour (Cinini et al., 2014). Among puppies, it has been shown that early life stress can permanently impair hippocampus-dependent learning and memory, in addition to increasing susceptibility to depression by reducing adult neurogenesis in the hippocampus (Karten et al., 2005).

Social isolation causes neurological changes that can induce social pain. Although neuroimaging studies show the activation of the dorsal anterior cingulate cortex and anterior insula in situations in which a person experiences physical and social pain, there is evidence that these same areas are activated in other stressful situations (Eisenberger, 2012b; Sturgeon \& Zautra, 2016). Thus, the anterior cingulate cortex and the anterior insula may have a broader role as a neural alarm system for survival (Eisenberger, 2012c). Almeida-Santos et al. (2019) demonstrated that animals in social isolation had alterations in glutamatergic neurotransmission in the olfactory bulb and the dorsal hippocampus, a neurochemical phenomenon that the authors associated with a deficit of social memory in addition to compromising communication between areas.

Interestingly, daily administration of acetaminophen compared to placebo in two studies showed reduced self-reports of social pain and reduced activity in both the dACC and AI when experiencing social exclusion (DeWall et al., 2010).

\section{The Treatment of Pain in the Period After the COVID-19 Pandemic}

The return to clinical pain management will have to address the biopsychosocial requirements related to period after the COVID-19 pandemic. The resumption of clinical pain management will have to address the biopsychosocial requirements of the period after the COVID-19 pandemic. Health care professionals will have to face the challenge of dealing with the overlap of physical and emotional pain and the possible process of catastrophic pain triggered or aggravated by the COVID-19 pandemic.

Beyond the typical challenges of self-managing a chronic disease, disease management has become significantly more complex with the implementation of social distancing, including individuals limiting unnecessary health care visits. It has led to confusion about how patients with chronic diseases should manage their disease 
and reduce the infection risk. This adaptative process directly impacts clinical symptoms, especially pain (Michaud et al., 2020).

The exposure of the population to traumas, such as witnessing and caring for seriously ill people, perceived life threats, mortality and mourning, and deaths of health professionals, can impair the mental health of individuals in the population and consequently increase the risks of developing psychological distress and progressing to have psychopathological disorders, including post-traumatic stress disorder (Neria \& Sullivan, 2011; Schultz \& Engelhardt, 2014).

Concerning the comprehension or elimination of pandemic-associated stigma, it is necessary to create strategies to address the psychological stress of the postpandemic period (Wang et al., 2020) and to identify its possible implications for the rehabilitation process and management of pain. In fact, there is evidence that shows increased levels of distress in response to suffering in people living in countries significantly affected by COVID-19 (Wang et al., 2020; Xiang et al., 2020).

Moreover, it is suggested that patients with suspected or confirmed SARS-CoV2 infection may experience fear and anxiety about the consequences of COVID-19, including death and severe physical disability. In addition, boredom, loneliness, and anger can be experienced by quarantined individuals. It is also suggested that the symptoms of anxiety and distress can be aggravated in these people; these symptoms can also occur in those in social isolation (Jahanshahi et al., 2020).

Studies show that individuals with severe illness or multiple comorbidities have higher psychological symptoms when faced a crisis. The impact of the COVID19 pandemic in Spain was assessed, and it was demonstrated that individuals who reported chronic illnesses had higher average levels of stress, anxiety, and depression compared to participants who did not report such illnesses (Ozamiz-Etxebarria et al., 2020). In this sense, post-pandemic patients may become more vulnerable to the frustrations and disabilities resulting from the disease and its physical symptoms, particularly pain. People with chronic pain, such as those with orthopaedic or rheumatic pathologies, often tend to manifest emotions of revulsion, anger, anxiety, or even depressive symptoms, which are not only reflected in the interaction with others but can also influence adverse symptomatology and disease progression (Ozamiz-Etxebarria et al., 2020).

In a study that evaluated patients' experiences with rheumatic diseases in the USA during the COVID-19 pandemic (Michaud et al., 2020), the most commonly reported emotions were anxiety, nervousness, worry, and fear. Some observed that anxiety/stress seemed to worsen their arthritis symptoms.

Approximately half of the patients in a North American cohort described significant disruption in their rheumatology care, including disrupted or postponed appointments and self-imposed or physician-suggested changes to medications (Sirotich et al., 2020). A change or interruption of treatment can cause worse chronic pain due to treatment failure and the psychic symptoms of the post-pandemic period.

The perceived intensity of painful symptoms is thus exacerbated by symptoms of disability, anxiety, depression, sleep disorders, poor quality of life, and health costs. Likewise, psychological distress has been identified as a possible way an episode of pain influences the development of persistent disabling symptoms (Park \& Park, 2020). Thus, health professionals may encounter the challenge of dealing with an 
increase in painful symptoms and the difficulty of reducing the levels of physical disability in patients. An excellent way to assess this intensity of pain perception is to adopt assessment instruments that evaluate broader aspects of pain.

Increasing evidence has shown that pain science education positively affects pain, disability, pain catastrophisation, movement limitations, and general health costs. For this, subjective and objective physical assessments must embrace a biopsychosocial approach instead of just a biomedical procedure. Patients with chronic pain suffer from severe fear, which should allow us to develop a treatment strategy that directly reduces aversive-stimulus-related emotions, thus improving these patients' physical and psychosocial well-being (Hall et al., 2011).

From a biopsychosocial view, psychological factors play an essential role in the onset and progression of chronic pain. The cognitive-behavioural model of avoiding fear in cases of chronic pain suggests that pain-related fear contributes to the development and maintenance of pain-related disability (Diener et al., 2016). Therefore, addressing the beliefs, cognitions, and behaviours associated with patients' pain symptoms has become a crucial issue for consideration during treatment, particularly during the treatment of chronic pain. These overlapping strategies impact pain surveillance, which can also lead to increases in the perception of pain severity.

Another point to be considered by the physician and physiotherapist in the post-pandemic period is the process of catastrophising pain, which worsens in the face of psychological suffering, whether linked to pain or not, maybe present or not even increase. According to Severeijns et al. (2001), patients with chronic pain who catastrophised reported greater pain intensity, felt more incapacitated by their pain problem, and experienced more psychological suffering. Catastrophisation was a powerful predictor of pain intensity, disability, and psychological distress, even when controlled by physical impairment. Thus, we can conclude that catastrophisation plays a crucial role in the experience of chronic pain, contributing significantly to the variation in pain intensity, pain-related disability, and psychological suffering.

There is growing evidence that when pain neuroscience education is provided to patients with chronic musculoskeletal pain, it can decrease pain, decrease pain catastrophisation, decrease disability, and improve physical performance (Puentedura \& Flynn, 2016; Wijma et al., 2016). Pain neuroscience education is increasingly used as part of a physiotherapeutic treatment in patients with chronic pain. A thorough clinical biopsychosocial assessment is recommended before pain neuroscience education to allow an adequate explanation of pain neurophysiology and biopsychosocial interactions in an interactive and patient-centred manner.

A broader analysis of pain should evaluate the somatic, cognitive, emotional, behavioural, and social factors and try to establish the most dominant mechanism of pain, as well as assess the provocative and disturbing biopsychosocial factors in patients with chronic pain. That approach allows the clinician to specifically classify patients and adapt the treatment plan (Wijma et al., 2016). Concerning that approach, a physiotherapist will understand the processes of pain in the post-pandemic period, observe its clinical implications, and evaluate and outline the most assertive behaviours. 
Inpatient consults will also require new approaches. For example, many consultations could occur in a nonessential way, without the need to see the patient in person, with most of the history being gathered via telephone or videoconference with the primary team members. The primary approach would be to assemble the patient's history, review the data, write notes, discuss the case, formulate a differential diagnosis, and recommend a treatment plan (Koumpouras \& Helfgott, 2020).

That procedure, initiated on an emergency basis for a pandemic period, can be implemented in the clinical monitoring of the patient between consultations and serve as a tool for interaction between the different health professionals involved in the treatment of pain (Koumpouras \& Helfgott, 2020). Examples of interventions that can effectively be delivered over the internet for patients with chronic pain include managing stress, addressing sleep disturbances, teaching mindfulness practices, cognitive strategies, pacing activities, social support programs, simple physical exercises, and observing a healthy lifestyle (Shanthanna et al., 2020).

It will be necessary to assess the impacts of COVID-19 on patients with chronic pain based on multidimensional and multi-professional information for better decision-making and for conducting rehabilitation processes. The acceleration of ongoing processes caused by pandemics can also lead to improvements in medical procedures and protocols, as well as improvements in the current understanding of the need for more suitable conduct based on the individual as a human being and not only focusing on the clinical symptoms of his/her health conditions, including pain.

\section{Neuroscience Evidence Related to Emotional and Social Pain During the COVID-19 Pandemic}

Emotion comes from the Latin words "ex + movere", which means "to move out". In a stressor event, such as the COVID-19 pandemic, this movement can be related to neuroplasticity (Orrù et al., 2020). Neuroplasticity-associated emotions are inherent to the social process of sensitisation (Garland et al., 2010). Regarding that point of view, it is apparent that the pandemic outbreak experienced by people in several regions of the world has had a crucial effect on the activity of neural pathways, as it can decrease conscious actions and hinder decision-making behaviours (O'Callaghan et al., 2017). Stressor-related processes, therefore, promote brain changes coming from scientific education, which happens to produce and preserve factors that have a social and emotional burden (Lupien et al., 2018).

In fact, the encephalon is sensitised by the external environment (Agorastos et al., 2018). Awareness comes from a critical and reflective process that results in experiences beyond the subject being merely informed. This perspective enables a broader understanding of human behaviour in the face of synaptic strengthening 
and weakening in emotional situations (Padilla et al., 2016), such as the COVID19 pandemic.

The pain arising from this phenomenon involves neural networks that affect memory, attention, self-regulation (risk assessment behaviours), and executive functions (decision making, planning, logical reasoning, and others) (Chedid, 2007; Cosenza, 2008; Guerra et al., 2004; Houzel, 2012; Ribeiro, 2013). Emotional and social pain can trigger adaptative responses during an organismenvironment interaction and exert influence on limbic neural systems underlying behaviour; modifying neural connectivity, neuroplasticity, and coding; and the modulation of behavioural responses related to perception, attention, memory, reasoning, and problem solving (Tyng et al., 2017).

The threat of the COVID-19 pandemic may also influence the development of the human brain, as it may influence cerebral neuroplasticity, with different peaks of synaptic density coming from environmental stimuli that occur during life (Blakemore \& Choudhury, 2006). Emotional pain comes from the possible cognitive "shake" that the COVID-19 pandemic can cause, reflecting on the neuroplastic capacity of the individual and, consequently, his/her social behaviour. In the upcoming post-pandemic period, the relationship between neuroplasticity and emotional pain experienced during the COVID-19 pandemic can be characterised by the involvement of health in its broad sense, encompassing physical, social, and mental aspects.

The impact of COVID-19 on behaviour and the development of the central nervous system involves the need for adaptive strategies of improved socioemotional and cognitive control capacity during life to avoid consequences such as pain (Compare et al., 2014). Thus, the neuroplasticity of emotion-related structures is currently under the threat stimuli represented by the COVID-19 pandemic. More specifically, the integrated activity of neural networks modulates autonomic responses and somatosensitivity (Christensen et al., 2020).

In this context, the limbic system, which, according to recent advances in neuroimaging, acts as the neuroanatomical basis of emotional behaviour, is highlighted as one of the systems possibly affected by the SARS-Cov2 virus. Moreover, limbic system involvement supports the concept that most of the ascending reticular activating system (ARAS) neurons situated in the brainstem will critically influence the activation of the cerebral cortex during pain suffering, elaboration of emotions, and threatening social situations (Venkatraman et al., 2017).

With socioemotional consideration and the consequent emotional pain in the face of the COVID-19 pandemic, it is possible to think about the direct influence on the emotions that people experience in the face of the prophylactic measure of social isolation, probably due to the importance of modulating the connection between the ventral striatum and the motor cortex through the nigrothalamic pathway (Aoki et al., 2019).

The COVID-19 pandemic, therefore, involves synaptic changes and the formation of new patterns of neural activity. The investigation of neuroplasticity has been constant in the scientific environment, primary investigations that seek a multisensory understanding (Oby et al., 2019). 


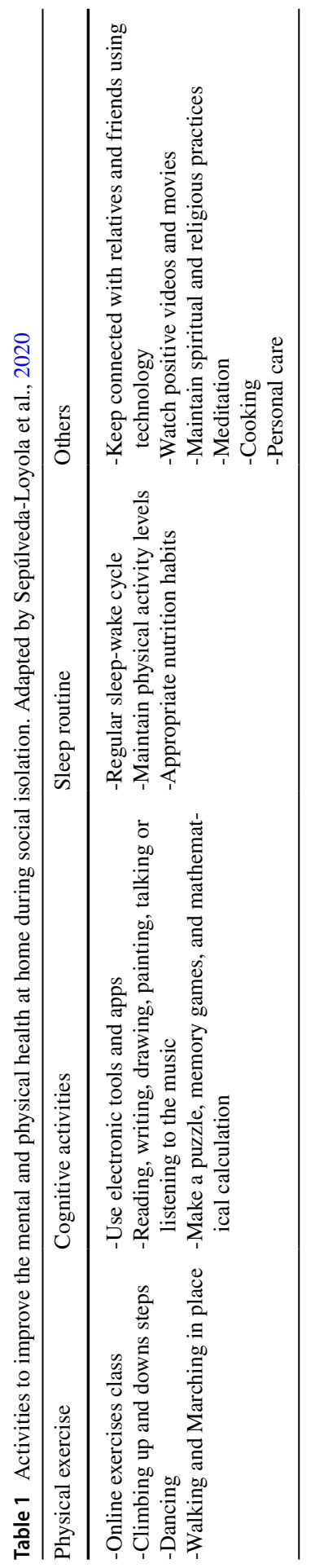


Notably, the number of publications involving emotional and social pain is growing; however, significant contributions are still small. Associated with the new context that the COVID-19 pandemic has imposed on daily life, directly influencing the emotional and cognitive aspects of human behaviour. Interaction with the social environment in which people live would be advantageous to improve our present understanding of human behaviour and the emotional pain arising from adaptation in a threatening situation. Neuroscientific investigations that improve the present understanding of human brain activity during the COVID-19 pandemic will contribute to new paths for a broader understanding of human behaviour during social isolation, highlighting the physical, emotional, and social pain experienced during the COVID-19 pandemic.

Summarising, considering the psychological impact of life, this review shares some recommendations. There are proposed different activities to improve mental and physical health at home, as seen in Table 1. In conclusion, the quarantine implied a radical change in the lifestyle of people. There was a reduction of social interaction, participation in exercise, and other practices, as religious or spiritual, which have negatively affected this population's mental and physical health (Vahia et al., 2020). Moreover, maintaining an active lifestyle at home is essential for health, especially for chronic diseases and comorbidities.

Acknowledgements We acknowledge all the authors of this review practicing social isolation in the COVID-19 pandemic.

Data Availability Data sharing not applicable to this article as no datasets were generated or analysed during the current study.

\section{Declarations}

Ethics Approval Not applicable.

Consent to Participate Not applicable.

Consent for Publication Not applicable.

Conflict of Interest The authors declare no competing interests.

\section{References}

Abad, A., da Silva, J., das Neves Braga, J., Medeiros, P., de Freitas, R., Coimbra, N.C., \& da Silva, J.A. (2020). Preparing for the COVID-19 mental health crisis in Latin America-Using early evidence from countries that experienced COVID-19 first. Advances in Infectious Diseases, 10, 40-44. https://doi.org/10.4236/aid.2020.103005

Administration on Aging 2013. A Profile of Older Americans: Retrieved from: http://www.aoa.gov/ Aging_Statistics/Profile/2013/docs/2013_Profile.pdf.

Agorastos, A., Pervanidou, P., Chrousos, G. P., \& Kolaitis, G. (2018). Early life stress and trauma: developmental neuroendocrine aspects of prolonged stress system dysregulation. Hormones, 17(4), 507520. https://doi.org/10.1007/s42000-018-0065-X 
Almada, R. C., \& Coimbra, N. C. (2015). Recruitment of striatonigral disinhibitory and nigrotectal inhibitory GABAergic pathways during the organization of defensive behavior by mice in a dangerous environment with the venomous snake Bothrops alternatus (Reptilia, Viperidae). Synapse, 69(6), 299-313. https://doi.org/10.1002/syn.21814

Almeida-Santos, A. F., Carvalho, V. R., Jaimes, L. F., de Castro, C. M., Pinto, H. P., Oliveira, T. P. D., Vieira, L. B., Moraes, M. F. D., \& Pereira, G. S. (2019). Social isolation impairs the persistence of social recognition memory by disturbing the glutamatergic tonus and the olfactory bulb-dorsal hippocampus coupling. Scientific Reports, 9(1), 1-13. https://doi.org/10.1038/s41598-018-36871-6

Anseloni, V. Z., Coimbra, N. C., Morato, S., \& Brandão, M. L. (1999). A comparative study of the effects of morphine in the dorsal periaqueductal gray and nucleus accumbens of rats submitted to the elevated plus-maze test. Experimental Brain Research, 129(2), 260-268. https://doi.org/10.1007/ s002210050896

Aoki, S., Smith, J. B., Li, H., Yan, X., Igarashi, M., Coulon, P., Wickens, J. R., Ruigrok, T. J., \& Jin, X. (2019). An open cortico-basal ganglia loop allows limbic control over motor output via the nigrothalamic pathway. eLife, 8, e49995. https://doi.org/10.7554/eLife.49995

Apkarian, A. V., Baliki, M. N., \& Geha, P. Y. (2009). Towards a theory of chronic pain. Progress in neurobiology, 87(2), 81-97. https://doi.org/10.1016/j.pneurobio.2008.09.018

Apkarian, A. V., Sosa, Y., Sonty, S., Levy, R. M., Harden, R. N., Parrish, T. B., \& Gitelman, D. R. (2004). Chronic back pain is associated with decreased prefrontal and thalamic gray matter density. Journal of Neuroscience, 24(46), 10410-10415. https://doi.org/10.1523/JNEUROSCI.2541-04.2004

Aslund, C., Starrin, B., \& Nilsson, K. W. (2010). Social capital in relation to depression, musculoskeletal pain, and psychosomatic symptoms: A cross-sectional study of a large population-based cohort of Swedish adolescents. BMC Public Health, 10(1), 715. https://doi.org/10.1186/1471-2458-10-715

Asmundson, G. J. G., Jacobson, S. J., Allerdings, M. D., \& Norton, G. R. (1996). Social phobia in disabled workers with chronic musculoskeletal pain. Behaviour Research and Therapy, 34(11-12), 939-943. https://doi.org/10.1016/S0005-7967(96)00055-1

Asmundson, G. J. G., \& Katz, J. (2009). Understanding the co-occurrence of anxiety disorders and chronic pain: State-of-the-art. Depression and Anxiety, 26(10), 888-901. https://doi.org/10.1002/ da. 20600

de Assis, M. (1998). O Alienista. Brasil. https://www.saraiva.com.br/o-alienista-livro-de-bolso-412920/p. Accessed 18 September 2020

Baliki, M. N., Chialvo, D. R., Geha, P. Y., Levy, R. M., Harden, R. N., Parrish, T. B., \& Apkarian, A. V. (2006). Chronic pain and the emotional brain: Specific brain activity associated with spontaneous fluctuations of intensity of chronic back pain. Journal of Neuroscience, 26(47), 12165-12173. https://doi.org/10.1523/JNEUROSCI.3576-06.2006

Bar, M., \& Neta, M. (2006). Humans prefer curved visual objects. Psychological Science, 17(8), 645648. https://doi.org/10.1111/j.1467-9280.2006.01759.x

Bar, M., \& Neta, M. (2007). Visual elements of subjective preference modulate amygdala activation. Neuropsychologia, 45(10), 2191-2200. https://doi.org/10.1016/j.neuropsychologia.2007.03.008

Baumeister, R. F., \& Leary, M. R. (1995). The need to belong: Desire for interpersonal attachments as a fundamental human motivation. Psychological Bulletin, 117(3), 497-529. https://doi.org/10.1037/ 0033-2909.117.3.497

Berg-Weger, M., \& Morley, J. (2020). Editorial: Loneliness in old age: An unaddressed health problem. Journal Nutrition, Health \& Aging, 24(3), 243-245. https://doi.org/10.1007/s12603-020-1323-6

Blakemore, S. J., \& Choudhury, S. (2006). Development of the adolescent brain: Implications for executive function and social cognition. Journal of Child Psychology and Psychiatry and Allied Disciplines, 47(3-4), 296-312. https://doi.org/10.1111/j.1469-7610.2006.01611.x

Bowman, J. M. (1994). Reactions to chronic low back pain. Issues in Mental Health Nursing, 15(4), 445453. https://doi.org/10.3109/01612849409006920

Brazilian Health Ministery. (2018). Biblioteca Virtual em Saúde. 18/5- Dia Nacional da Luta Antimanicomial. Ministério da Saúde. 17 de maio de 2018. Disponível em Acessado em: 15 de setembro de 2020.

Breivik, H., Collett, B., Ventafridda, V., \& Cohen, R. (2006). Survey of chronic pain in Europe: Prevalence,impact on daily life and treatment. European Journal of Pain, 10, 287-333. https://doi. org/10.1016/j.ejpain.2005.06.009

Brown, J. L., Sheffield, D., Leary, M. R., \& Robinson, M. E. (2003). Social support and experimental pain. Psychosomatic Medicine, 65(2), 276-283. https://doi.org/10.1097/01.PSY.0000030388. 62434.46 
Cacioppo, J. T., Hawkley, L. C., Norman, G. J., \& Berntson, G. G. (2011). Social isolation. Annals of the New York Academy of Sciences, 1231(1), 17-22. https://doi.org/10.1111/j.1749-6632.2011.06028.x

Cauda, F., Torta, D. M. E., Sacco, K., Geda, E., D’Agata, F., Costa, T., Duca, S., Geminiani, G., \& Amanzio, M. (2012). Shared "core" areas between the pain and other task-related networks. PLoS ONE, 7(8), e41929. https://doi.org/10.1371/journal.pone.0041929

dos Cardoso, F. S., de P Teixeira, L. E. P., de Freitas, R. L., Abad, A., Campos, L. A. M., \& Da Silva, J. A. (2021). Peritraumatic distress caused by the COVID-19 pandemic: Comparison between genders and countries - Brazil and Portugal. Mankind Quarterly, 62(2), 239-254. https://doi.org/10. 46469/mq.2021.62.2.2

Che, X., Cash, R., Chung, S., Fitzgerald, P. B., \& Fitzgibbon, B. M. (2018). Investigating the influence of social support on experimental pain and related physiological arousal: A systematic review and meta-analysis. Neuroscience and Biobehavioral Reviews, 92, 437-452. https://doi.org/10.1016/j. neubiorev.2018.07.005

Chedid, K. A. K. (2007). PSICOPEDAGOGIA, EDUCAÇÃO E NEUROCIÊNCIAS. Revista de Psicologia, 24(75), 298-300 www.katiachedid.com.br. Accessed 18 September 2020

Christensen, J. S., Wild, H., Kenzie, E. S., Wakeland, W., Budding, D., \& Lillas, C. (2020). Diverse autonomic nervous system stress response patterns in childhood sensory modulation. Frontiers in Integrative Neuroscience, 14, 6. https://doi.org/10.3389/fnint.2020.00006

Cinini, S. M., Barnabe, G. F., Galvã£o-Coelho, N., de Medeiros, M. A., Perez-Mendes, P., Sousa, M. B. C., Covolan, L., \& Mello, L. E. (2014). Social isolation disrupts hippocampal neurogenesis in young non-human primates. Frontiers in Neuroscience, 8, 45. https://doi.org/10.3389/fnins.2014. 00045

Compare, A., Zarbo, C., Shonin, E., Van Gordon, W., \& Marconi, C. (2014). Emotional regulation and depression: A potential mediator between heart and mind. Cardiovascular Psychiatry and Neurology, 2014, 324374. https://doi.org/10.1155/2014/324374

Cosenza, R. M.(2008). A Evolução das ideias sobre a relação entre cérebro, comportamento e cognição | Neuropsicologia | Córtex Cerebral. (Artmed, Ed.). Porto Alegre. https://pt.scribd.com/doc/57485 206/A-Evolucao-das-ideias-sobre-a-relacao-entre-cerebro-comportamento-e-cognicao. Accessed 18 September 2020

Coyle, C. E., \& Dugan, E. (2012). Social isolation, loneliness and health among older adults. Journal of Aging and Health, 24(8), 1346-1363. https://doi.org/10.1177/0898264312460275

Cornwell, E. Y., \& Waite, L. J. (2009). Social disconnectedness, perceived isolation, and health among older adults. Journal of Health and Social Behavior, 50(1), 31-48. https://doi.org/10.1177/00221 4650905000103

Courtin, E., \& Knapp, M. (2017). Social isolation, loneliness and health in old age: a scoping review. Health \& Social Care in the Community, 25(3), 799-812. https://doi.org/10.1111/hsc.12311

Craig, A. D. (2003). A new view of pain as a homeostatic emotion. Trends in Neurosciences, 26(6), 303307. https://doi.org/10.1016/S0166-2236(03)00123-1

Crespi, F., Wright, I. K., \& Möbius, C. (1992). Isolation rearing of rats alters release of 5-hydroxytryptamine and dopamine in the frontal cortex: An in vivo electrochemical study. Experimental Brain Research, 88(3), 495-501. https://doi.org/10.1007/BF00228179

Croezen, S., Avendano, M., Burdorf, A., \& van Lenthe, F. J. (2015). Social participation and depression in old age: a fixed-effects analysis in 10 European countries. American Journal of Epidemiology, 182(2), 168-176. https://doi.org/10.1093/aje/kwv015

Danzmann, P., Danzmann, P. S., da Silva, A. C. P., \& Guazina, F. M. N. (2020). Atuação do psicólogo na saúde mental da população diante da pandemia / Psychologist performance in the mental health of the population in the face of the pandemic. Journal of Nursing and Health, 10(4). https://doi.org/ 10.15210/jonah.v10i4.18945

Defeudis, F. V., Defeudis, P. A., \& Somoza, E. (1976). Altered analgesic responses to morphine in differentially housed mice. Psychopharmacology, 49(1), 117-118. https://doi.org/10.1007/BF00427482

DeVries, A. C., Glasper, E. R., \& Detillion, C. E. (2003). Social modulation of stress responses. Physiology and Behavior, 79(3), 399-407. https://doi.org/10.1016/S0031-9384(03)00152-5

de Freitas, R. L., Salgado-Rohner, C. J., Hallak, J. E. C., de Souza Crippa, J. A., \& Coimbra, N. C. (2013). Involvement of prelimbic medial prefrontal cortex in panic-like elaborated defensive behaviour and innate fear-induced antinociception elicited by GABAA receptor blockade in the dorsomedial and ventromedial hypothalamic nuclei: role of the endocannabinoid CB1 receptor. International Journal of Neuropsychopharmacology, 16(8), 1781-1798. https://doi.org/10.1017/ S1461145713000163 
de Paiva Teixeira, L., Freitas, R., Abad, A., da Silva, J., Antonelli-Ponti, M., Bastos, S., Mármora, C., Campos, L., Paiva, S., \& da Silva, J.A. (2020). Psychological impacts related to stress and fear during the COVID-19 pandemic: Cardiovascular diseases, diabetes and psychological disorders as risk factors. World Journal of Neuroscience, 10, 191-205. https://doi.org/10.4236/wjns.2020.104019

DeWall, C. N., MacDonald, G., Webster, G. D., Masten, C. L., Baumeister, R. F., Powell, C., Combs, D., Schurtz, D. R., Stillman, T. F., Tice, D. M., \& Eisenberger, N. I. (2010). Acetaminophen reduces social pain: Behavioral and neural evidence. Psychological Science, 21(7), 931-937. https://doi. org/10.1177/0956797610374741

Diener, I., Kargela, M., \& Louw, A. (2016). Listening is therapy: Patient interviewing from a pain science perspective. Physiotherapy Theory Pract, 32, 356-367.

DiGiovanni, C., Conley, J., Chiu, D., \& Zaborski, J. (2004). Factors influencing compliance with quarantine in Toronto during the 2003 SARS outbreak. Biosecurity and Bioterrorism: Biodefense Strategy, Practice, and Science, 2(4), 265-272. https://doi.org/10.1089/bsp.2004.2.265

Douglas, H., Georgiou, A., \& Westbrook, J. (2017). Social participation as an indicator of successful aging: An overview of concepts and their associations with health. Australian Health Review, 41(4), 455-462. https://doi.org/10.1071/AH16038

Eisenberger, N. I. (2012a). The pain of social disconnection: Examining the shared neural underpinnings of physical and social pain. Nature Reviews Neuroscience, 13(6), 421-434. https://doi.org/10.1038/ nrn3231

Eisenberger, N. I. (2012b). The neural bases of social pain: Evidence for shared representations with physical pain. Psychosomatic Medicine, 74(2), 126-135. https://doi.org/10.1097/PSY.0b013e3182 464dd 1

Eisenberger, N. I. (2012c). The neural bases of social pain: Evidence for shared representations with physical pain. Psychosomatic Medicine, 74(2), 126-135. https://doi.org/10.1097/PSY.0b013e3182 464dd 1

Eisenberger, N. I., Gable, S. L., \& Lieberman, M. D. (2007a). Functional magnetic resonance imaging responses relate to differences in real-world social experience. Emotion, 7(4), 745-754. https://doi. org/10.1037/1528-3542.7.4.745

Eisenberger, N. I., Jarcho, J. M., Lieberman, M. D., \& Naliboff, B. D. (2006). An experimental study of shared sensitivity to physical pain and social rejection. Pain, 126(1-3), 132-138. https://doi.org/10. 1016/j.pain.2006.06.024

Eisenberger, N. I., Taylor, S. E., Gable, S. L., Hilmert, C. J., \& Lieberman, M. D. (2007b). Neural pathways link social support to attenuated neuroendocrine stress responses. NeuroImage, 35(4), 16011612. https://doi.org/10.1016/j.neuroimage.2007.01.038

Evers, A. W. M., Kraaimaat, F. W., Geenen, R., Jacobs, J. W. G., \& Bijlsma, J. W. J. (2003). Pain coping and social support as predictors of long-term functional disability and pain in early rheumatoid arthritis. Behaviour Research and Therapy, 41(11), 1295-1310. https://doi.org/10.1016/S00057967(03)00036-6

Falconi-Sobrinho, L. L., dos Anjos-Garcia, T., Elias-Filho, D. H., \& Coimbra, N. C. (2017). Unravelling cortico-hypothalamic pathways regulating unconditioned fear-induced antinociception and defensive behaviours. Neuropharmacology, 113, 367-385. https://doi.org/10.1016/J.NEURO PHARM.2016.10.001

Feldman, J. B. (2004). The neurobiology of pain, affect and hypnosis. American Journal of Clinical Hypnosis, 46(3), 187-200. https://doi.org/10.1080/00029157.2004.10403599

Ferreira-Valente, M. A., Pais-Ribeiro, J. L., \& Jensen, M. P. (2014). Associations between psychosocial factors and pain intensity, physical functioning, and psychological functioning in patients with chronic pain: A cross-cultural comparison. Clinical Journal of Pain, 30(8), 713-723. https://doi.org/10.1097/AJP.0000000000000027

Foltz, E. L., \& White, L. E. (1968). The role of rostral cingulumotomy in "pain" relief. International journal of neurology, 6(3-4), 353-373.

Fone, K. C. F., Shalders, K., Fox, Z. D., Arthur, R., \& Marsden, C. A. (1996). Increased 5-HT2C receptor responsiveness occurs on rearing rats in social isolation. Psychopharmacology, 123(4), 346-352. https://doi.org/10.1007/BF02246645

Freitas, R.L., Uribe-Mariño, A., Castiblanco-Urbina, M.A., Elias-Filho, D.H., \& Coimbra, N.C. (2009). GABA(A) receptor blockade in dorsomedial and ventromedial nuclei of the hypothalamus evokes panic-like elaborated defensive behaviour followed by innate fear-induced antinociception. Brain Research, 1305, 118-131. https://doi.org/10.1016/j.brainres.2009.09.096 
Friedman, D. P., Murray, E. A., O’Neill, J. B., \& Mishkin, M. (1986). Cortical connections of the somatosensory fields of the lateral sulcus of macaques: Evidence for a corticolimbic pathway for touch. Journal of Comparative Neurology, 252(3), 323-347. https://doi.org/10.1002/cne. 902520304

Garland, E. L., Fredrickson, B., Kring, A. M., Johnson, D. P., Meyer, P. S., \& Penn, D. L. (2010). Upward spirals of positive emotions counter downward spirals of negativity: Insights from the broaden-and-build theory and affective neuroscience on the treatment of emotion dysfunctions and deficits in psychopathology. Clinical Psychology Review, 30(7), 849-864. https://doi.org/ 10.1016/j.cpr.2010.03.002

Grande, L. A., Loeser, J. D., Ozuna, J., \& Ashleigh, A. S. A. (2004). Complex regional pain syndrome as a stress response. Pain, 110, 495-498.

Guerra, L. B., Pereira, A. H., \& Lopes, M. Z. (2004). NEUROEDUCA-Inserção da Neurobiologia na Educação. https://www.ufmg.br/congrext/Educa/Educa113.pdf

Hadland, K. A., Rushworth, M. F. S., Gaffan, D., \& Passingham, R. E. (2003). The effect of cingulate lesions on social behaviour and emotion. Neuropsychologia, 41(8), 919-931. https://doi.org/10. 1016/S0028-3932(02)00325-1

Hall, A. M., Kamper, S. J., Maher, C. G., Latimer, J., Ferreira, M. L., \& Nicholas, M. K. (2011). Symptoms of depression and stress mediate the effect of pain on disability. Pain, 152, 10441051. https://doi.org/10.1016/j.pain.2011.01.014

Hammond, D. (1989). New Insights Regarding Organization of Spinal Cord Pain Pathways. Physiology, 4(3), 98-101. https://doi.org/10.1152/physiologyonline.1989.4.3.98

Han, J. S., Li, W., \& Neugebauer, V. (2005). Critical role of calcitonin gene-related peptide 1 receptors in the amygdala in synaptic plasticity and pain behavior. Journal of Neuroscience, 25(46), 10717-10728. https://doi.org/10.1523/JNEUROSCI.4112-05.2005

Hawthorne, G., De Morton, N., \& Kent, P. (2013). Back pain and social isolation: Cross-sectional validation of the friendship scale for use in studies on low back pain. Clinical Journal of Pain, 29(3), 245-252. https://doi.org/10.1097/AJP.0b013e31824b3aed

Heikkinen, R. L., \& Kauppinen, M. (2004). Depressive symptoms in late life: A 10-year follow-up. Archives of Gerontology and Geriatrics, 38(3), 239-250. https://doi.org/10.1016/j.archger. 2003.10.004

Holt-Lunstad, J., Smith, T. B., \& Layton, J. B. (2010). Social relationships and mortality risk: A metaanalytic review. PLoS Medicine, 7(7), e1000316. https://doi.org/10.1371/journal.pmed.1000316

Houzel, S. H. (2012). O Cérebro Nosso de Cada Dia - Descobertas da Neurociência Sobre a Vida Cotidiana . (Vieira\&Lent, Ed.) (2 $2^{\mathrm{a}}$.). Brasil. https://www.saraiva.com.br/o-cerebro-nosso-decada-dia-descobertas-da-neurociencia-sobre-a-vida-cotidiana-2-ed-2012-4091600/p. Accessed 18 September 2020

Iglesias-López, E., García-Isidoro, S., \& Castellanos-Sánchez, V. O. (2021). COVID-19 pandemic: Pain, quality of life and impact on public health in the confinement in Spain. Annald of Palliative Medicine, 10(4), 4338-4353. https://doi.org/10.21037/apm-20-2514

Ismail, I. I., Kamel, W. A., \& Al-Hashel, J. Y. (2021). Association of COVID-19 pandemic and rate of cognitive decline in patients with dementia and mild cognitive impairment: a cross-sectional study. Gerontology and Geriatric Medicine, 7, 23337214211005223. https://doi.org/10.1177/ 23337214211005223

Jahanshahi, A. A., Dinani, M. M., Madavani, A. N., Li, J., \& Zhang, S. X. (2020). The distress of Iranian adults during the Covid-19 pandemic - More distressed than the Chinese and with different predictors. Brain, Behavior, and Immunity, 87, 124-125. https://doi.org/10.1016/j.bbi.2020.04.081

Ji, G., Sun, H., Fu, Y., Li, Z., Pais-Vieira, M., Galhardo, V., \& Neugebauer, V. (2010). Cognitive impairment in pain through amygdala-driven prefrontal cortical deactivation. Journal of Neuroscience, 30(15), 5451-5464. https://doi.org/10.1523/JNEUROSCI.0225-10.2010

Johnson, K. V. A., \& Dunbar, R. I. M. (2016). Pain tolerance predicts human social network size. Scientific Reports, 6(1), 1-5. https://doi.org/10.1038/srep25267

Jones, G. H., Hernandez, T. D., Kendall, D. A., Marsden, C. A., \& Robbins, T. W. (1992). Dopaminergic and serotonergic function following isolation rearing in rats: Study of behavioural responses and postmortem and in vivo neurochemistry. Pharmacology Biochemistry and Behavior, 43(1), 17-35. https://doi.org/10.1016/0091-3057(92)90635-S

Julius, D. (2001). Molecular mechanisms of nociception. Nature, 413, 203-210. https://doi.org/10.1038/ 35093019 
Kandel, E. R., Schwartz, J. H., \& Jessell, T. M. (2000). Principles of neural science ((4th ed.). ed.). McGraw-Hill Companies. https://doi.org/10.1007/s13398-014-0173-7.2

Kamper, S. J., Apeldoorn, A. T., Chiarotto, A., Smeets, R. J., Ostelo, R. W., Guzman, J., \& van Tulder, M. W. (2015). Multidisciplinary biopsychosocial rehabilitation for chronic low back pain: Cochrane systematic review and meta-analysis. BMJ., 18(350), h444. https://doi.org/10.1136/bmj.h444

Karayannis, N. V., Baumann, I., Sturgeon, J. A., Melloh, M., \& Mackey, S. C. (2019). The impact of social isolation on pain interference: A longitudinal study. Annals of Behavioral Medicine, 53(1), 65-74. https://doi.org/10.1093/abm/kay017

Karten, Y. J. G., Olariu, A., \& Cameron, H. A. (2005). Stress in early life inhibits neurogenesis in adulthood. Trends in Neurosciences, 28(4), 171-172. https://doi.org/10.1016/j.tins.2005.01.009

Knaster, P., Karlsson, H., Estlander, A. M., \& Kalso, E. (2012). Psychiatric disorders as assessed with SCID in chronic pain patients: The anxiety disorders precede the onset of pain. General Hospital Psychiatry, 34(1), 46-52. https://doi.org/10.1016/j.genhosppsych.2011.09.004

Korkut, S., \& Ülker, T. (2021). The effect of pain experienced during the COVID-19 infection on the fear of pain and quality of life. Pain Management Nursing., 20, S1524-9042(21)00194-6. https://doi. org/10.1016/j.pmn.2021.08.007

Koumpouras, F., \& Helfgott, S. (2020). Stand together and deliver: Challenges and opportunities for rheumatology education during the COVID-19 pandemic. Arthritis and Rheumatology, 72(7), 1064-1066. https://doi.org/10.1002/art.41278

Le Bars, D., Gozariu, M., \& Cadden, S. W. (2001). Animal models of nociception. Pharmacological reviews, 53(4), 597-652. https://doi.org/10.1111/j.1476-5381.2011.01386.X

Li, X. Y., Ko, H. G., Chen, T., Descalzi, G., Koga, K., Wang, H., Lee, K., Collingridge, G. L., Kaang, B. K., \& Zhuo, M. A. (2010). Alleviating neuropathic pain hypersensitivity by inhibiting PKM $\zeta$ in the anterior cingulate cortex. Science, 330(6009), 1400-1404. https://doi.org/10.1126/science.1191792

Lougon, M. (2006). Psiquiatria institucional: do hospício à reforma psiquiátrica. Cadernos de Saúde Pública. Editora Fiocruz. https://doi.org/10.1590/s0102-311x2008000300028

Lee, S., Chan, L. Y., Chau, A. M., Kwok, K. P., \& Kleinman, A. (2005). The experience of SARS-related stigma at Amoy Gardens. Social Science \& Medicine (1982), 61(9), 2038-2046. https://doi.org/10. 1016/j.socscimed.2005.04.010

Loyola, W. S., Camillo, C. A., Torres, C. V., \& Probst, V. S. (2017). Effects of an exercise model based on functional circuits in an older population with different levels of social participation. Geriatrics Gerontology Internatrional, 18(2), 216-223. https://doi.org/10.1111/ggi.13167

Lucchelli, P. E., Cattaneo, A. D., \& Zattoni, J. (1978). Effect of capsule colour and order of administration of hypnotic treatments. European Journal of Clinical Pharmacology, 13(2), 153-155. https:// doi.org/10.1007/BF00609760

Lumley, M. A., Cohen, J. L., Borszcz, G. S., Cano, A., Radcliffe, A. M., Porter, L. S., et al. (2011). Pain and emotion: A biopsychosocial review of recent research. Journal of Clinical Psychology, 67(9), 942-968. https://doi.org/10.1002/jclp.20816

Lupien, S. J., Juster, R. P., Raymond, C., \& Marin, M. F. (2018). The effects of chronic stress on the human brain: From neurotoxicity, to vulnerability, to opportunity. Frontiers in Neuroendocrinology, 49, 91-105. https://doi.org/10.1016/j.yfrne.2018.02.001

MacDonald, G., \& Leary, M. R. (2005). Why does social exclusion hurt? The relationship between social and physical pain. Psychological Bulletin, 131(2), 202-223. https://doi.org/10.1037/0033-2909. 131.2.202

Malvestio, R. B., Medeiros, P., Negrini-Ferrari, S. E., Oliveira-Silva, M., Medeiros, A. C., Padovan, C. M., Luongo, L., Maione, S., Coimbra, N. C., \& de Freitas, R. L. (2021). Cannabidiol in the prelimbic cortex modulates the comorbid condition between the chronic neuropathic pain and depression-like behaviour in rats: The role of medial prefrontal cortex 5-HT1A and CB1 receptors. Brain Research Bulletin, 174, 323-338. https://doi.org/10.1016/j.brainresbull.2021.06.017

Marchand, S. (2012). International Assossiation of study of pain. The Phenomenon of pain. IASP Press. Seatle.

Master, S. L., Eisenberger, N. I., Taylor, S. E., Naliboff, B. D., Shirinyan, D., \& Lieberman, M. D. (2009). A picture's worth: Partner photographs reduce experimentally induced pain. Psychological Science, 20(11), 1316-1318. https://doi.org/10.1111/j.1467-9280.2009.02444.X

Medeiros, P., de Freitas, R.L., Boccella, S., Iannotta, M., Belardo, C., Mazzitelli, M., Romano, R., De Gregorio, D., Coimbra, N. C., Palazzo, E., \& Maione, S. (2019a). Characterization of the sensory, affective, cognitive, biochemical, and neuronal alterations in a modified chronic constriction injury 
model of neuropathic pain in mice. Journal of Neuroscience Research, 98(2), 338-352. https://doi. org/10.1002/jnr.24501

Medeiros, P., Negrini-Ferrari, S. E., Medeiros, A. C., Ferreira, L. L., da Silva, J. R. T., da Silva, J. A., Coimbra, N.C., \& de Freitas, R.L. (2019b). The primary motor cortex stimulation attenuates cold allodynia in a chronic peripheral neuropathic pain condition in Rattus norvegicus. World Journal of Neuroscience, 09(03), 138-152. https://doi.org/10.4236/wjns.2019.93009

Medeiros, P., Negrini-Ferrari, S. E., Palazzo, E., Maione, S., Ferreira, S. H., de Freitas, R. L., \& Coimbra, N. C. (2019c). N-methyl-d-aspartate receptors in the prelimbic cortex are critical for the maintenance of neuropathic pain. Neurochemical Research, 44(9), 2068-2080. https://doi.org/10.1007/ s11064-019-02843-Z

Meléndez, J. C., Satorres, E., Reyes-Olmedo, M., Delhom, I., Real, E., \& Lora, Y. (2020). Emotion recognition changes in a confinement situation due to COVID-19. Journal of Environmental Psychology, 72, 101518. https://doi.org/10.1016/j.jenvp.2020.101518

Mellado, B. H., Falcone, A. C. M., Poli-Neto, O. B., Silva, R. E. J. C., Nogueira, A. A., \& Candido-DosReis, F. J. (2016). Social isolation in women with endometriosis and chronic pelvic pain. International Journal of Gynecology and Obstetrics, 133(2), 199-201. https://doi.org/10.1016/j.ijgo.2015. 08.024

Melloh, M., Elfering, A., Käser, A., Salathé, C. R., Barz, T., Aghayev, E., Röder, C., \& Theis, J. C. (2013a). Depression impacts the course of recovery in patients with acute low-back pain. Behavioral Medicine, 39(3), 80-89. https://doi.org/10.1080/08964289.2013.779566

Melloh, M., Elfering, A., Stanton, T. R., Käser, A., Salathé, C. R., Barz, T., Röder, C., \& Theis, J. C. (2013b). Who is likely to develop persistent low back pain? A longitudinal analysis of prognostic occupational factors. Work, 46(3), 297-311. https://doi.org/10.3233/WOR-131672

Messlinger, K. (1997). Was ist ein Nozizeptor? Anaesthesist., 46(2), 142-153. https://doi.org/10.1007/ s001010050384

Metz, A. E., Yau, H.-J., Centeno, M. V., Apkarian, A. V., \& Martina, M. (2009). Morphological and functional reorganization of rat medial prefrontal cortex in neuropathic pain. Proceedings of the National Academy of Sciences, 106(7), 2423-2428. https://doi.org/10.1073/pnas.0809897106

Michaud, K., Wipfler, K., Shaw, Y., Simon, T. A., Cornish, A., England, B. R., Ogdie, A., \& Katz, P. (2020). Experiences of patients with rheumatic diseases in the United States during early days of the COVID -19 pandemic. ACR Open Rheumatology, 2(6), 335-343. https://doi.org/10.1002/acr2. 11148

Millan, M. J. (1999). The induction of pain: An integrative review. Progress in Neurobiology, 57(1), 1-164. https://doi.org/10.1016/S0301-0082(98)00048-3

Morley, J. E., \& Vellas, B. (2020). COVID-19 and older adults. Journal of Nutrition and Health Aging., 24(4), 364-365. https://doi.org/10.1007/s12603-020-1349-9

Neria, Y., \& Sullivan, G. M. (2011). Understanding the mental health effects of indirect exposure to mass trauma through the media. JAMA - Journal of the American Medical Association, 306(12), 13741375. https://doi.org/10.1001/jama.2011.1358

O'Callaghan, C., Kveraga, K., Shine, J. M., Adams, R. B., \& Bar, M. (2017). Predictions penetrate perception: Converging insights from brain, behaviour and disorder. Consciousness and Cognition, 47, 63-74. https://doi.org/10.1016/j.concog.2016.05.003

Oby, E. R., Golub, M. D., Hennig, J. A., Degenhart, A. D., Tyler-Kabara, E. C., Yu, B. M., Chase, S. M., \& Batista, A. P. (2019). New neural activity patterns emerge with long-term learning. Proceedings of the National Academy of Sciences of the United States of America, 116(30), 15210-15215. https://doi.org/10.1073/pnas.1820296116

Orrù, G., Ciacchini, R., Gemignani, A., \& Conversano, C. (2020). Psychological intervention measures during the COVID-19 pandemic. Clinical Neuropsychiatry, 17(2), 76-79. https://doi.org/10.36131/ CN20200208

Otis, J. D., Keane, T. M., \& Kerns, R. D. (2003). An examination of the relationship between chronic pain and post-traumatic stress disorder. Journal of Rehabilitation Research and Development, 40(5), 397-405. https://doi.org/10.1682/jrrd.2003.09.0397

Ozamiz-Etxebarria, N., Dosil-Santamaria, M., Picaza-Gorrochategui, M., \& Idoiaga-Mondragon, N. (2020). Stress, anxiety, and depression levels in the initial stage of the COVID-19 outbreak in a population sample in the northern Spain. Cadernos de Saúde Pública, 36(4). https://doi.org/10. 1590/0102-311X00054020

Padilla, S. L., Qiu, J., Soden, M. E., Sanz, E., Nestor, C. C., Barker, F. D., Quintana, A., Zweifel, L. S., Rønnekleiv, O. K., Kelly, M. J., \& Palmiter, R. D. (2016). Agouti-related peptide neural circuits 
mediate adaptive behaviors in the starved state. Nature Neuroscience, 19(5), 734-741. https://doi. org/10.1038/nn.4274

Panksepp, J. (1998). Affective neuroscience: the foundations of human and animal emotions . (Oxford University Press, Ed.). New York. https://books.google.com.br/books?id=qqcRGagyEuAC\& printsec $=$ frontcover $\& \mathrm{hl}=\mathrm{pt}-\mathrm{BR} \&$ source $=\mathrm{gbs} \_\mathrm{ge} \_$summary_r\&cad $=0 \# \mathrm{v}=$ onepage $\& \mathrm{q} \& \mathrm{f}=\mathrm{false}$. Accessed 18 September 2020

Panksepp, J., Herman, B. H., Conner, R., Bishop, P. E., \& Scott, J. P. (1978). The biology of social attachments: opiates alleviate separation distress. Biological Psychiatry, 13(5), 607-618.

Park, S. C., \& Park, Y. C. (2020). Mental health care measures in response to the 2019 novel coronavirus outbreak in Korea. Psychiatry Investigation, 17(2), 85-86. https://doi.org/10.30773/pi.2020.0058

Patterson, A. C., \& Veenstra, G. (2010). Loneliness and risk of mortality: A longitudinal investigation in Alameda County, California. Social Science and Medicine, 71(1), 181-186. https://doi.org/10. 1016/j.socscimed.2010.03.024

Peyron, R., Laurent, B., \& García-Larrea, L. (2000). Functional imaging of brain responses to pain. A review and meta-analysis (2000). Neurophysiologie Clinique, 30(5), 263-288. https://doi.org/10. 1016/S0987-7053(00)00227-6

Price, D. D. (2000). Psychological and neural mechanisms of the affective dimension of pain. Science, 288(5472), 1769-1772. https://doi.org/10.1126/science.288.5472.1769

Puentedura, E. J., \& Flynn, T. (2016). Combining manual therapy with pain neuroscience education in the treatment of chronic low back pain: A narrative review of the literature. Physiotherapy Theory and Practice, 32(5), 408-414. https://doi.org/10.1080/09593985.2016.1194663

Melzack, R., \& Casey, K.L. (1968). Sensory, motivational, and central control determinants of pain. International Symposium on the Skin Senses. Springfield. https://www.researchgate.net/publi cation/285016812_Sensory_motivational_and_central_control_determinants_of_pain_Kenshalo_ DR_editor_The_skin_senses_proceedings_Springfield_Illinois_Charles_C. Accessed 18 September 2020

Raja, S. N., Carr, D. B., Cohen, M., Finnerup, N. B., Flor, H., Gibson, S., Keefe, F. J., Mogil, J. S., Ringkamp, M., Sluka, K. A., Song, X. J., Stevens, B., Sullivan, M. D., Tutelman, P. R., Ushida, T., \& Vader, K. (2020). The revised International Association for the Study of Pain definition of pain: Concepts, challenges, and compromises. Pain, 161(9), 1976-1982. https://doi.org/10.1097/j.pain. 0000000000001939

Reddan, M. C., Young, H., Falkner, J., López-Solà, M., \& Wager, T. D. (2020). Touch and social support influence interpersonal synchrony and pain. Social Cognitive and Affective Neuroscience, 15(10), 1064-1075. https://doi.org/10.1093/scan/nsaa048

Ribeiro, S. (2013). Tempo de cérebro. Estudos Avancados, 27(77), 7-22. https://doi.org/10.1590/S010340142013000100002

Salles, M. M., \& Barros, I. S. (2013). Transforming Mental Health Care and users' everyday life: from the psychiatric hospital to the Psychosocial Care Center. Saúde debate, 37(97), 324-335. https:// www.scielo.br/scielo.php?script=sci_arttext\&pid=S0103-11042013000200014. Accessed 18 Sept 2020

Saraceno, B. (1999). Libertando identidades: da reabilitação psicossocial à cidadania possível. (TeCorá, Ed.) (2nd ed.). Rio de Janeiro.

Schapira, K., McClelland, H. A., Griffiths, N. R., \& Newell, D. J. (1970). Study on the effects of tablet colour in the treatment of anxiety states. British Medical Journal, 2(5707), 446-449. https://doi. org/10.1136/bmj.2.5707.446

Schultz, C., \& Engelhardt, M. (2014). Anatomy of the hippocampal formation. In The Hippocampus in Clinical Neuroscience, 34, 6-17. https://doi.org/10.1159/000360925

Schwartz, L., \& Slater, M. A. (1991). The impact of chronic pain on the spouse: Research and clinical implications. Holistic Nursing Practice, 6(1), 9-16. https://doi.org/10.1097/00004650-19911 0000-00005

Severeijns, R., Vlaeyen, J. W. S., Van Den Hout, M. A., \& Weber, W. E. J. (2001). Pain catastrophizing predicts pain intensity, disability, and psychological distress independent of the level of physical impairment. Clinical Journal of Pain, 17(2), 165-172. https://doi.org/10.1097/00002508-20010 6000-00009

Sepúlveda-Loyola, W., Rodríguez-Sánchez, I., Pérez-Rodríguez, P., Ganz, F., Torralba, R., Oliveira, D. V., \& Rodríguez-Mañas, L. (2020). Impact of social isolation due to COVID-19 on health in older people: mental and physical effects and recommendations. Journal Nutritional and Health Aging., 24(9), 938-947. https://doi.org/10.1007/s12603-020-1469-2 
Shankar, A., Hamer, M., McMunn, A., \& Steptoe, A. (2013). Social isolation and loneliness: Relationships with cognitive function during 4 years of follow-up in the English longitudinal study of ageing. Psychosomatic Medicine, 75(2), 161-170. https://doi.org/10.1097/PSY.0b013e31827f09cd

Shanthanna, H., Strand, N. H., Provenzano, D. A., Lobo, C. A., Eldabe, S., Bhatia, A., Wegener, J., Curtis, K., Cohen, S. P., \& Narouze, S. (2020). Caring for patients with pain during the COVID-19 pandemic: Consensus recommendations from an international expert panel. Anaesthesia, 75(7), 935-944. https://doi.org/10.1111/anae.15076

Shaw, W. S., Means-Christensen, A. J., Slater, M. A., Webster, J. S., Patterson, T. L., Grant, I., Garfin, S. R., Wahlgren, D. R., Patel, S., \& Atkinson, J. H. (2010). Psychiatric disorders and risk of transition to chronicity in men with first onset low back pain. Pain Medicine, 11(9), 1391-1400. https://doi. org/10.1111/j.1526-4637.2010.00934.x

Silvia, P. J., \& Barona, C. M. (2009). Do people prefer curved objects? Angularity, expertise, and aesthetic preference. Empirical Studies of the Arts, 27(1), 25-42. https://doi.org/10.2190/em.27.1.b

Sirotich, E., Dillingham, S., Grainger, R., Hausmann, J. S., Robinson, P., Yazdany, J., et al. (2020). Capturing patient-reported outcomes during the COVID-19 pandemic: Development of the COVID19 Global Rheumatology Alliance Patient Experience Survey. Arthritis Care and Research, 72(7), 871-873. https://doi.org/10.1002/acr.24257

Smith, J. A., \& Osborn, M. (2007). Pain as an assault on the self: An interpretative phenomenological analysis of the psychological impact of chronic benign low back pain. Psychology and Health, 22(5), 517-534. https://doi.org/10.1080/14768320600941756

Snelling, J. (1994). The effect of chronic pain on the family unit. Journal of Advanced Nursing, 19(3), 543-551. https://doi.org/10.1111/j.1365-2648.1994.tb01119.x

Soiza, R. L., Scicluna, C., \& Thomson, E. C. (2021). Efficacy and safety of COVID-19 vaccines in older people. Age Ageing., 50(2), 279-283. https://doi.org/10.1093/ageing/afaa274

Steptoe, A., Shankar, A., Demakakos, P., \& Wardle, J. (2013). Social isolation, loneliness, and all-cause mortality in older men and women. Proceedings of the National Academy of Sciences of the United States of America, 110(15), 5797-5801. https://doi.org/10.1073/pnas.1219686110

Stevens, F. L., Hurley, R. A., \& Taber, K. H. (2011). Anterior cingulate cortex: Unique role in cognition and emotion. Journal of Neuropsychiatry and Clinical Neurosciences, 23(2), 121-125. https://doi. org/10.1176/jnp.23.2.jnp121

Sturgeon, J. A., \& Zautra, A. J. (2016). Social pain and physical pain: Shared paths to resilience. Pain management, 6(1), 63-74. https://doi.org/10.2217/pmt.15.56

Tang, J., \& Gibson, S. J. (2005). A psychophysical evaluation of the relationship between trait anxiety, pain perception, and induced state anxiety. Journal of Pain, 6(9), 612-619. https://doi.org/10. 1016/j.jpain.2005.03.009

Tomioka, K., Kurumatani, N., \& Hosoi, H. (2015). Social participation and the prevention of decline in effectance among community-dwelling elderly: A population-based cohort study. PLoS One, 10(9), e0139065. https://doi.org/10.1371/journal.pone.0139065

Tow, P. M., \& Whitty, C. W. (1953). Personality changes after operations on the cingulate gyrus in man. Journal of Neurology, Neurosurgery, and Psychiatry, 16(3), 186-193. https://doi.org/10.1136/jnnp. 16.3.186

Treede, R. D., Kenshalo, D. R., Gracely, R. H., \& Jones, A. K. P. (1999). The cortical representation of pain. Pain, 79(2-3), 105-111. https://doi.org/10.1016/S0304-3959(98)00184-5

Tuboly, G., Benedek, G., \& Horvath, G. (2009). Selective disturbance of pain sensitivity after social isolation. Physiology and Behavior, 96(1), 18-22. https://doi.org/10.1016/j.physbeh.2008.07.030

Tyng, C. M., Amin, H. U., Saad, M. N. M., \& Malik, A. S. (2017). The influences of emotion on learning and memory. Frontiers in Psychology, 8, 1454. https://doi.org/10.3389/fpsyg.2017.01454

Ullah, F., dos Anjos-Garcia, T., dos Santos, I. R., Biagioni, A. F., \& Coimbra, N. C. (2015). Relevance of dorsomedial hypothalamus, dorsomedial division of the ventromedial hypothalamus and the dorsal periaqueductal gray matter in the organization of freezing or oriented and non-oriented escape emotional behaviors. Behavioural Brain Research, 293, 143-152. https://doi.org/10.1016/j.bbr. 2015.07.013

Vahia, I. V., Blazer, D. G., Smith, G. S., Karp, J. F., Steffens, D. C., Forester, B. P., Tampi, R., Agronin, M., Jeste, D. V., \& Reynolds 3rd., C. F. (2020). COVID-19, Mental health and aging: A need for new knowledge to bridge science and service. American Journal of Geriatric Psychiatry, 28(7), 695-697. https://doi.org/10.1016/j.jagp.2020.03.007 
Valtorta, N. K., Kanaan, M., Gilbody, S., \& Hanratty, B. (2016). Loneliness, social isolation and social relationships: What are we measuring? A novel framework for classifying and comparing tools. BMJ Open, 6(4), e010799. https://doi.org/10.1136/bmjopen-2015-010799

Van Den Berg, C. L., Van Ree, J. M., Spruijt, B. M., \& Kitchen, I. (1999). Effects of juvenile isolation and morphine treatment on social interactions and opioid receptors in adult rats: Behavioural and autoradiographic studies. European Journal of Neuroscience, 11(9), 3023-3032. https://doi.org/10. 1046/j.1460-9568.1999.00717.x

Venkatraman, A., Edlow, B. L., \& Immordino-Yang, M. H. (2017). The brainstem in emotion: A review. Frontiers in Neuroanatomy, 11, 15. https://doi.org/10.3389/fnana.2017.00015

Villemure, C., \& Bushnell, M. C. (2009). Mood influences supraspinal pain processing separately from attention. Journal of Neuroscience, 29(3), 705-715. https://doi.org/10.1523/JNEUROSCI.3822-08. 2009

Vogt, B. A., Sikes, R. W., \& Vogt, L. J. (1993). Anterior cingulate cortex and the medial pain system. In Neurobiology of Cingulate Cortex and Limbic Thalamus (pp. 313-344). Birkhäuser Boston. https://doi.org/10.1007/978-1-4899-6704-6_11

Wager, T. D., van Ast, V. A., Hughes, B. L., Davidson, M. L., Lindquist, M. A., \& Ochsner, K. N. (2009). Brain mediators of cardiovascular responses to social threat, Part II: Prefrontal-subcortical pathways and relationship with anxiety. NeuroImage, 47(3), 836-851. https://doi.org/10.1016/j.neuro image.2009.05.044

Wan, X., Woods, A. T., Salgado-Montejo, A., Velasco, C., \& Spence, C. (2015). Assessing the expectations associated with pharmaceutical pill colour and shape. Food Quality and Preference, 45, 171-182. https://doi.org/10.1016/j.foodqual.2015.06.009

Wang, C., Pan, R., Wan, X., Tan, Y., Xu, L., Ho, C. S., \& Ho, R. C. (2020). Immediate psychological responses and associated factors during the initial stage of the 2019 coronavirus disease (COVID19) epidemic among the general population in China. International Journal of Environmental Research and Public Health, 17(5), 1729. https://doi.org/10.3390/ijerph17051729

Wang, J., Lloyd-Evans, B., Giacco, D., Forsyth, R., Nebo, C., Mann, F., \& Johnson, S. (2017). Social isolation in mental health: a conceptual and methodological review. Social Psychiatry and Psychiatric Epidemiology, 52(12), 1451-1461. https://doi.org/10.1007/s00127-017-1446-1

Way, B. M., Taylor, S. E., \& Eisenberger, N. I. (2009). Variation in the $\mu$-opioid receptor gene (OPRM1) is associated with dispositional and neural sensitivity to social rejection. Proceedings of the National Academy of Sciences of the United States of America, 106(35), 15079-15084. https://doi. org/10.1073/pnas.0812612106

Westerman, S. J., Gardner, P. H., Sutherland, E. J., White, T., Jordan, K., Watts, D., \& Wells, S. (2012). Product design: Preference for rounded versus angular design elements. Psychology \& Marketing, 29(8), 595-605. https://doi.org/10.1002/mar.20546

Wijma, A. J., van Wilgen, C. P., Meeus, M., \& Nijs, J. (2016). Clinical biopsychosocial physiotherapy assessment of patients with chronic pain: The first step in pain neuroscience education. Physiotherapy Theory and Practice, 32(5), 368-384. https://doi.org/10.1080/09593985.2016.1194651

Wilson, R. S., Krueger, K. R., Arnold, S. E., Schneider, J. A., Kelly, J. F., Barnes, L. L., Tang, Y., \& Bennett, D. A. (2007). Loneliness and risk of Alzheimer disease. Archives of General Psychiatry, 64(2), 234-240. https://doi.org/10.1001/archpsyc.64.2.234

Wilson, N., Kvalsvig, A., Barnard, L. T., \& Baker, M. G. (2020). Case-fatality risk estimates for COVID19 calculated by using a lag time for fatality. Emerging Infectious Disease, 26(6), 1339-1441. https://doi.org/10.3201/eid2606.200320

Xiang, Y. T., Yang, Y., Li, W., Zhang, L., Zhang, Q., Cheung, T., \& Ng, C. H. (2020). Timely mental health care for the 2019 novel coronavirus outbreak is urgently needed. The Lancet Psychiatry, 7(3), 228-229. https://doi.org/10.1016/S2215-0366(20)30046-8

Yoon, M. K., Kim, S. Y., Ko, H. S., \& Lee, M. S. (2016). System effectiveness of detection, brief intervention and refer to treatment for the people with post-traumatic emotional distress by MERS: A case report of community-based proactive intervention in South Korea. International Journal Mental Health System, 10, 51. https://doi.org/10.1186/s13033-016-0083-5

Yip, P. S. F., Cheung, Y. T., Chau, P. H., \& Law, Y. W. (2010). The impact of epidemic outbreak: The case of severe acute respiratory syndrome (SARS) and suicide among older adults in Hong Kong. Crisis, 31(2), 86-92. https://doi.org/10.1027/0227-5910/a000015

Zhai, P., Ding, Y., Wu, X., Long, J., Zhong, Y., \& Li, Y. (2020). The epidemiology, diagnosis and treatment of COVID-19. International Journal of Antimicrobial Agents, 55(5), 105955.https://doi.org/ 10.1016/j.ijantimicag.2020.105955 
Zugaib, J., Coutinho, M. R., Ferreira, M. D., \& Menescal-de-oliveira, L. (2014). Glutamate / GABA balance in ACC modulates the nociceptive responses of vocalization: An expression of affectivemotivationalcomponent of pain in guinea pigs. Physiology \& Behavior, 126, 8-14. https://doi.org/10. 1016/j.physbeh.2013.12.004

Zugaib, J., \& Menescal-de-Oliveira, L. (2017). Cholinergic / opioid interaction in anterior cingulate cortex reduces the nociceptive response of vocalization in guinea pigs. Brain Research, 1671, 131137.https://doi.org/10.1016/j.brainres.2017.07.013

\title{
Authors and Affiliations
}

\section{Priscila Medeiros ${ }^{1,2}\left[\right.$ (D) Ana Carolina Medeiros ${ }^{1,2,3}[$. Jade Pisssamiglio Cysne Coimbra ${ }^{4}$. Lucas Emmanuel Pedro de Paiva Teixeira ${ }^{5}$. Carlos José Salgado-Rohner ${ }^{6}$. José Aparecido da Silva ${ }^{7}$. Norberto Cysne Coimbra ${ }^{1,3}$ (D) Renato Leonardo de Freitas ${ }^{2,8,3}$}

\author{
Ana Carolina Medeiros \\ medeiros96.carol@gmail.com \\ Jade Pisssamiglio Cysne Coimbra \\ jade_coimbra@outlook.com \\ Lucas Emmanuel Pedro de Paiva Teixeira \\ lucas.teixeira@unifal-mg.edu.br \\ Carlos José Salgado-Rohner \\ carlos.salgado2@unisabana.edu.co \\ José Aparecido da Silva \\ jadsilva@ffclrp.usp.br \\ Norberto Cysne Coimbra \\ nccoimbr@fmrp.usp.br
}

1 Laboratory of Neuroanatomy and Neuropsychobiology, Department of Pharmacology, Ribeirão Preto Medical School of the University of São Paulo (FMRP-USP), Av. Bandeirantes, 3900, São Paulo, Ribeirão Preto 14049-900, Brazil

2 Laboratory of Neurosciences of Pain \& Emotions and Multi-User Centre of Neuroelectrophysiology, Department of Surgery and Anatomy, Ribeirão Preto Medical School of the University of São Paulo, Av. Bandeirantes, 3900, São Paulo, Ribeirão Preto 14049-900, Brazil

3 Behavioural Neurosciences Institute (INeC), Av. do Café, 2450, São Paulo, Ribeirão Preto 14050-220, Brazil

4 Pontificial Catholic University of Campinas (PUC-Campinas), Prof Dr Euryclides de Jesus Zerbini Str., 1516, Parque Rural Fazenda Santa Cândida, Campinas, São Paulo 13087-571, Brazil

5 Institute of Motricity Sciences, Federal University of Alfenas (UNIFAL), Alfenas, MG, Brazil

6 NeuroSmart Lab, International School of Economics and Administrative Sciences, Universidad de La Sabana, Chia, Colombia

7 Laboratory of Psychophysics, Perception, Psychometrics, and Pain, Department of Psychology, Ribeirão Preto School of Philosophy, Sciences and Literature of the University of São Paulo (FFCLRP-USP), São Paulo, Ribeirão Preto 14049-901, Brazil

8 Biomedical Sciences Institute, Federal University of Alfenas (UNIFAL-MG), Gabriel Monteiro da Silva Str., 700, Alfenas, Minas Gerais 37130-000, Brazil 